\title{
Informalidade e segmentação no mercado de trabalho brasileiro: evidências quantílicas sob alocação endógena
}

Informality and segmentation in the Brazilian labor market: quantilic evidences under endogenous allocation

\author{
Cassiano Ricardo Dalberto (1) \\ Jader Fernandes Cirino (2) \\ (1) Universidade Federal de Santa Catarina \\ (2) Universidade Federal de Viçosa
}

\begin{abstract}
This study investigates the occurrence of incomes segmentation between formal and informal workers in Brazil, considering two distinct groups: employees, and selfemployed together with employers. While for the first group the formality criterion is the signed work contract, for the second is the contribution to the social security. Using information from the National Household Sample Survey (PNAD) for the years of 2002 and 2012, and applying a model of quantile treatment effect under endogeneity, we try to verify if there are differences of income between formal and informal workers that can be explained solely by the individual allocation into one sector or another. The results indicate the occurrence of segmentation in a large part of the income distribution for both groups and in both periods. In addition, this phenomenon occurs more intensely in the lower quantiles of the distribution, that is, among lower income workers.
\end{abstract}

\section{Keywords}

informal workers; instrumental variables; quantile treatment effect.

JEL Codes J52; J46.

\section{Resumo}

O presente trabalho investiga a ocorrência de segmentação de rendimentos entre trabalhadores brasileiros formais e informais, considerando dois grupos distintos: os empregados e os autônomos juntamente com empregadores. Enquanto para o primeiro grupo o critério de formalidade é a carteira de trabalho assinada, para o segundo é a contribuição para a previdência. Utilizando as informações da Pesquisa Nacional por Amostra de Domicílios (PNAD) para os anos de 2002 e 2012 e aplicando um modelo de efeitos de tratamento quantílicos sob endogenia, procura-se verificar se existem diferenças de rendimento entre formais e informais que podem ser explicadas unicamente pela alocação do individuo entre um ou outro setor. Os resultados encontrados apontam para a ocorrência de segmentação em grande parte da distribuição de rendimentos para ambos os grupos e nos dois periodos, sendo que tal fenômeno ocorre de maneira mais intensa nos quantis inferiores da distribuição, isto é, trabalhadores de menor rendimento.

\section{Palavras-chave}

trabalhadores informais; variáveis instrumentais; efeito de tratamento quantílico.

Códigos JEL J52; J46. 


\section{Introdução}

A informalidade no mercado de trabalho é um tema que suscita debates em diferentes países e contextos, em grande parte devido à ausência de consenso tanto no que se refere à definição do termo quanto dos seus reflexos sobre o mercado de trabalho. A explicação para a ocorrência de diferenciais de rendimentos entre trabalhadores formais e informais tampouco é consensual. Uma das abordagens mais utilizadas na literatura diz respeito à segmentação do mercado de trabalho sob a hipótese de que trabalhadores com dotações de atributos idênticas podem receber salários diferenciados, de acordo com o setor em que estão alocados.

No que tange aos conceitos de informalidade, as diferentes definições podem conduzir a resultados substancialmente díspares, o que gera uma dificuldade adicional para a comparação entre pesquisas. Uma classificação tradicional na literatura brasileira enquadra como trabalhadores informais aqueles que não possuem carteira de trabalho assinada. ${ }^{1}$ Outras abordagens abrangem dentro da informalidade também os trabalhadores por conta própria, ou ainda o conjunto dos trabalhadores que não contribui para a previdência social. ${ }^{2}$

No cenário brasileiro, a dimensão da informalidade tem sido de grande relevância ao longo das últimas décadas. Segundo Ulyssea (2006), após alguma elevação na proporção de trabalhadores sem carteira assinada no começo dos anos de 1980, atingindo quase $30 \%$ da população então ocupada, o nível de informalidade permaneceu relativamente estável até o fim daquela década. Nos anos de 1990, tal nível voltou a crescer, chegando a cerca de $40 \%$ na virada do século e quase metade da força de trabalho, se considerarmos os trabalhadores por conta própria. Já na década de 2000, a informalidade passa a cair de modo significativo e segundo diversos critérios, conforme mostram Barbosa Filho e Veloso (2016).

Dados apresentados por Leone (2010) para 2008 mostram que, dos 92,3 milhões de trabalhadores ocupados, 15,9 milhões eram trabalhadores sem carteira, 4,9 milhões eram trabalhadores domésticos sem registro, e outros 18,7 milhões constituíam a parcela dos trabalhadores por conta própria. A soma desses indivíduos respondia por $42,8 \%$ da ocupação naquele ano e,

1 Por exemplo, em Barros e Varandas (1987), Barros, Reis e Rodriguez (1990), Pero (1992), Barros, Mello e Pero (1993) e Fernandes (1996).

2 Como em Kassouf (1998). 
se for acrescentado à soma os 12,9 milhões de indivíduos que se distribuem entre empregadores, trabalhadores para consumo próprio e autoconstrução e trabalhadores não remunerados, chega-se à constatação de que $56,77 \%$ de toda a força de trabalho não possuía contrato formal de trabalho.

Entretanto, não parece razoável considerar todos os trabalhadores por conta própria e os empregadores como informais, sobretudo por uma ótica de precariedade do trabalho. ${ }^{3}$ Como tal parcela de trabalhadores não possui carteira de trabalho assinada, torna-se necessário buscar outro critério que possa classificá-los de acordo com a formalidade. O critério disponível que provavelmente mais se aproxima de tal definição é a contribuição para a previdência. Dado que, sendo um contribuinte, o trabalhador desfruta de benefícios oferecidos pelo sistema de seguridade - como aposentadoria, salário-maternidade e auxílio doença - parece ser razoável enquadrá-lo no mercado de trabalho formal, ainda que não possua carteira de trabalho. Assim, torna-se possível distinguir empregadores e trabalhadores por conta própria em formais ou informais de acordo com sua contribuição ou não para a previdência.

Dessa forma, o presente trabalho, ao abordar empregados, autônomos e empregadores, utiliza diferentes definições de formalidade, de acordo com cada grupo. Para empregados, utiliza-se o critério tradicional da carteira de trabalho. Para trabalhadores por conta própria e empregadores, vale-se da contribuição para a previdência, com vistas a selecionar aqueles dentro de tal grupo que não estejam amparados por um sistema de seguridade e, portanto, encontrem-se em posição mais vulnerável.

Considerando esses critérios, de acordo com dados da Pesquisa Nacional por Amostra de Domicílios de 2012, entre o grupo de trabalhadores ora considerados como empregados (empregados com carteira; outros com carteira; empregados sem declaração de carteira; domésticos com carteira; domésticos sem carteira; e domésticos sem declaração de carteira), $33,65 \%$ daqueles que trabalharam no período não possuíam carteira de trabalho assinada. Já entre os autônomos e empregadores, $71,23 \%$ não contribuíam para a previdência. Nota-se que a dimensão da informalidade é bastante diferente entre os dois grupos, mas não se pode perder de vista que os critérios de formalidade são diferentes, apesar de próximos sob a ótica da precariedade do trabalho.

3 A ideia de precariedade do trabalho enquanto característica do trabalho informal é utilizada pela OIT (2002) e apresentada na seção 2 deste trabalho. 
Dada a dimensão do mercado de trabalho informal, são necessárias análises que o contrastem com o mercado formal. Tradicionalmente, tais análises remetem ao argumento da segmentação do mercado de trabalho, atestando que os trabalhadores formais possuem vantagens de rendimentos sobre os informais, levando-se em consideração indivíduos com a mesma dotação de atributos. A existência de tal diferencial em favor da formalidade implica a ocorrência de barreiras para a entrada em tal grupo. Em outros termos, isso significa que os trabalhadores, de modo geral, enfrentam mais dificuldades para entrar no mercado de trabalho formal do que no informal, e que a ênfase analítica deve recair sobre a estrutura dos mercados de trabalho e aspectos institucionais.

Tal hipótese contrasta com aquela preconizada pela visão (neo)clássica, de que a distribuição de rendimentos no mercado de trabalho é contínua em relação aos atributos produtivos dos indivíduos e de que, portanto, a educação e a experiência deles constituem os fatores explicativos primordiais sobre a distribuição dos rendimentos do trabalho. A ideia de um mercado de trabalho segmentado pontua que, embora tal ideia possa ser válida dentro de mercados de trabalho específicos, ela não é necessariamente válida para o conjunto mais amplo. Isto é, há uma descontinuidade entre os mercados de trabalho que pode ser resumida pela noção de um mercado dual, sendo um deles mais favorecido/desenvolvido que o outro. Nesse sentido, os trabalhadores do mercado mais favorecido observam retornos maiores aos seus atributos produtivos do que aqueles situados no mercado menos desenvolvido. No presente âmbito, esses mercados equivalem aos setores formal e informal, respectivamente.

As investigações a respeito da ocorrência ou não de segmentação formal-informal se dão majoritariamente em países em desenvolvimento, onde o mercado de trabalho informal tende a ser maior e ter mais relevância. ${ }^{4}$ Para o caso brasileiro, autores como Sedlacek, Barros e Varandas (1990), Carneiro e Henley (2001), e Menezes Filho, Mendes e Almeida (2004), por exemplo, apresentam evidências de que o mercado de trabalho nacional não é segmentado entre formais e informais.

Por outro lado, diversos trabalhos apontam para a ocorrência de segmentação em desfavor da informalidade. Um dos artigos pioneiros sobre esse assunto é o de Barros e Varandas (1987), que verificam altas dispa4 Ver, por exemplo, os trabalhos de Maloney (1999), Pratap e Quintin (2002) e Tansel e Kan (2012) para o México, Argentina e Turquia, respectivamente. 
ridades entre os salários dos trabalhadores formais e informais homens, chefes de família e residentes em áreas urbanas de regiões metropolitanas brasileiras, para diversos grupos de ocupação. Ao contrário do esperado pelos autores, o gap salarial a favor da formalidade é maior para os quantis mais elevados da distribuição do salário. Entretanto, tais resultados, isoladamente, não tornam evidente a ocorrência de segmentação, dada a ausência de controles para atributos produtivos dos trabalhadores, como educação e experiência.

Por sua vez, Tannuri-Pianto e Pianto (2002), utilizando regressões quantílicas com correção para o problema de seleção amostral, encontram salários bastante inferiores para os trabalhadores brasileiros informais em relação aos formais, principalmente para aqueles na base da distribuição de rendimentos. Para os autores, parece haver pouco espaço para tais indivíduos no setor formal, o que torna difícil negar a ocorrência de segmentação.

Similarmente, Bargain e Kwenda (2009), analisando dados em painel tanto para o Brasil, como para o México e para a África do Sul, encontram resultados que apontam para uma penalização nos ganhos dos trabalhadores informais nos quantis inferiores da distribuição salarial, o que pode indicar ocorrência de segmentação para os trabalhadores de rendimentos mais baixos nesses países.

A diversidade de resultados existentes e os contrastes entre os mesmos lança considerável incerteza sobre quais são as políticas mais adequadas nesse contexto. Além disso, nota-se na literatura uma carência de abordagens que tratem a alocação do trabalhador na formalidade ou na informalidade como endógena. Sendo razoável assumir que em muitos casos o indivíduo tenha margem de escolha para decidir entre ser formal ou informal - especialmente no caso da contribuição para previdência como critério -, análises que desconsiderem tal aspecto estão sujeitas a resultados enviesados. Assim, suscita-se a necessidade de utilizar métodos compatíveis com a alocação endógena do trabalhador, a fim de abordar mais adequadamente a questão.

Além disso, é importante levar em consideração que mensurações apenas sobre rendimentos médios, ainda que controladas por diversas características do trabalhador e de seu contexto, constituem uma informação bastante limitada, pois pouco têm a informar a respeito da situação daqueles cujos rendimentos estão distantes dessa média, especialmente quando situados nas posições mais extremas. Análises que abordem os diferenciais 
de rendimento em diferentes pontos de sua distribuição fornecem uma caracterização mais completa do fenômeno em questão, permitindo observar a possível ocorrência de segmentação e de diferenças nos retornos aos atributos produtivos entre formais e informais, tanto para os trabalhadores com menor rendimento quanto para os com maior.

À medida que a informalidade constitui parcela elevada do mercado de trabalho brasileiro, a compreensão sobre seus possíveis diferenciais de rendimentos em relação ao setor formal torna-se objeto de relevância, apontando eventuais deficiências e potencialidades em políticas públicas que visem melhorar a situação dos trabalhadores do conjunto da economia. Se de fato ocorre segmentação de rendimentos entre os setores, então políticas que amenizem ou eliminem tal problema são bem-vindas, sobretudo pela redução de possíveis barreiras à formalidade, permitindo maior acesso a postos de trabalho mais seguros.

Nesse sentido, o presente trabalho se vale de um método de efeitos de tratamento quantílicos sob endogeneidade, com vistas a investigar a ocorrência de diferenciais de rendimentos dos homens no Brasil entre os setores formal e informal nos diferentes quantis de sua distribuição, para os anos de 2002 e 2012, de modo a atestar se há ocorrência de segmentação entre tais grupos, bem como analisar a evolução do fenômeno ao longo do período em questão. A escolha por abordar apenas os homens se dá em função do problema de seleção amostral, que surge sobretudo na oferta feminina de trabalho, em que os efeitos de preço de reserva são mais fortes, de modo que análises de rendimento que não envolvam tratamento para tal questão estarão sujeitas a vieses. Dada a impossibilidade de tratar esse problema no presente caso, optou-se por restringir a análise apenas à força de trabalho masculina.

Além deste primeiro item, o restante do presente trabalho divide-se em outras quatro seções: a segunda aborda os conceitos teóricos por trás da teoria do mercado de trabalho segmentado, bem como da informalidade enquanto critério de dualidade; a terceira apresenta a base de dados utilizada, as variáveis selecionadas e uma análise descritiva das mesmas; a quarta apresenta os resultados obtidos por meio dos efeitos de tratamento quantílicos sob endogenia (cuja metodologia é apresentada no Apêndice 1), bem como discute-os sob a luz do contexto e das teorias apresentadas; a quinta seção, por fim, sumariza as análises feitas e traz considerações finais para o trabalho. 


\section{0 mercado de trabalho segmentado e a informalida- de como critério delimitador}

Diferentemente da teoria do capital humano proposta por Schultz (1961) e Becker (1962), a teoria do mercado de trabalho dual, ou segmentado, não enfatiza o papel da educação e do treinamento na determinação da renda. Sua preocupação é com a estrutura alocativa e o funcionamento do mercado de trabalho. Nesse sentido, a educação perde importância na explicação da distribuição de renda, mas ainda desempenha papel relevante na alocação de trabalhadores entre diferentes segmentos. Dito de outra forma, a indivíduos com diferentes níveis educacionais podem estar associados a "sinais" diferentes que influenciam no acesso a diferentes mercados de trabalho (Lima, 1980).

Para Leontaridi (1998), a ideia de segmentação desafia a explicação clássica do funcionamento do mercado de trabalho, atestando que o mesmo é fragmentado e que as características institucionais e sociais têm influência relevante sobre o emprego e os salários. Essa visão, portanto, muda o foco da abordagem do mercado de trabalho do lado da oferta (visão clássica e neoclássica) para o lado da demanda. Em outras palavras, ao invés de enfatizar fatores como a produtividade individual (relacionada às decisões individuais de investimento em capital humano) e a preferência por lazer, a teoria do mercado de trabalho segmentado questiona a existência de uma ligação direta entre o salário e os atributos produtivos do indivíduo, e considera fatores como a organização industrial, o mercado de produtos, as condições tecnológicas e os sistemas de regulação do mercado de trabalho como muito mais influentes sobre a estrutura dos empregos.

O surgimento de tal ideia não é recente. Uma revisão teórico-empírica sobre a segmentação do mercado de trabalho pode ser encontrada em Leontaridi (1998), que traça desde as origens de tal visão em Cairnes (1878) e Stuart Mill (1885). A partir das décadas de 1960 e 1970, essa abordagem passa a ganhar mais proeminência. Enquanto que um grupo de economistas $^{5}$ passa a utilizar a ideia de um mercado de trabalho dual para explicar a persistência do desemprego e da pobreza urbana nos Estados Unidos, trabalhos como o de Doeringer e Piore (1971) passaram a postular a existência de um mercado interno, cujas características o diferem do restante

5 Entre os quais, Averitt (1968), Bluestone (1970) e Harrison (1972).

v.28 n.2 2018 Nova Economia 
do mercado de trabalho, causando diferenciais de salários observados que não seriam meramente fruto das diferenças nos atributos individuais, mas sim de características institucionais. Tais teorias, portanto, supõe uma "dicotomização" do mercado de trabalho entre um setor mais favorecido, o primário, e outro menos desenvolvido, o secundário.

Para Doeringer e Piore (1971) o mercado de trabalho primário seria constituído pelos mercados de trabalho interno bem desenvolvidos - isto é, com melhores condições de trabalho -, cujos empregos são governados por regras formais (geralmente estabelecidas pelos sindicatos) e informais (hábitos, noções de justiça e equidade, reciprocidade, etc.). Conjuntamente, tais regras definem os salários, os requisitos associados a cada posto de trabalho e a estrutura organizacional dos mesmos, protegendo, assim, o mercado interno contra as pressões da concorrência do mercado externo, ou secundário, e portanto limitando a mobilidade entre ambos.

Estabelecida a definição do mercado de trabalho segmentado, procura-se caracterizar a informalidade para, a partir disso, poder enquadrá-la como expressão de dualidade do mercado de trabalho. Para tanto, é necessário que o trabalho informal possa ser considerado equivalente ao setor secundário (ou seja, dotado das características de tal setor), e a partir disso busca-se evidenciar que há alguma segmentação entre tal setor e o setor primário, no caso o mercado de trabalho formal.

Historicamente, a Organização Internacional do Trabalho (OIT) utiliza o termo "setor informal" pela primeira vez em 1972, para designar aqueles trabalhadores mais pobres, em situações de trabalho não reconhecidas, protegidas ou reguladas pelas autoridades públicas (OIT, 1972). Posteriormente, em documento do Programa Regional del Empleo para América Latina y Caribe (PREALC), órgão associado à OIT, Mezzera (1990, p. 3) estabelece a seguinte definição para o setor informal, adaptada à realidade latino-americana: "The informal sector is a set of productive units which the main characteristic is their very limited access to capital, resulting in a very low capital-labour ratio, in which most of the members of the excess labour supply find employment". O próprio autor prossegue para a constatação de que nos países latino-americanos a informalidade é fator segmentacional no mercado de trabalho, apresentando a distinção das razões capital/trabalho (K/L) num contexto dual, baseado em evidências empíricas, como pode ser visualizado na Figura 1. 


\section{Figura 1 Segmentação de acordo com o nível da relação capital/trabalho}

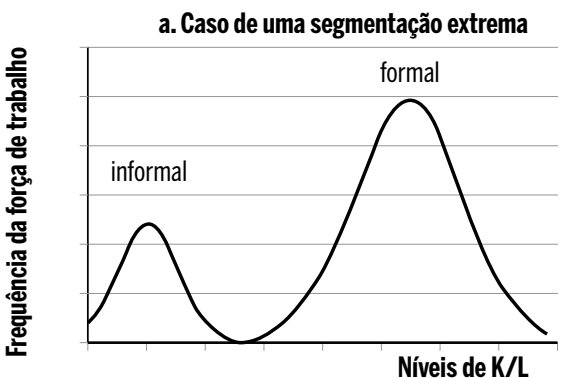

b. Caso de uma segmentação suave

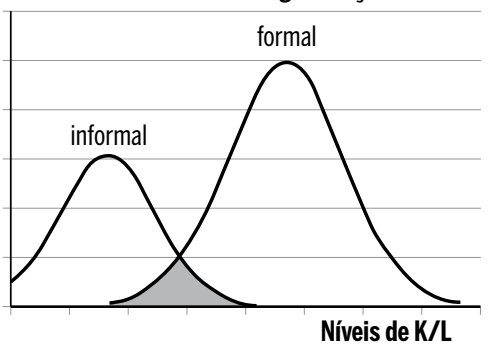

Fonte: Elaboração própria, adaptado de Mezzera (1990).

No caso "a", em nenhum nível de K/L ocorre a sobreposição entre as curvas que representam os trabalhadores formais e informais. Já no caso "b", a área sombreada representa níveis de $\mathrm{K} / \mathrm{L}$ em que existem tanto trabalhadores formais quanto informais. Mezzera (1990) argumenta que tais condições evidenciam o caráter bastante distinto entre os dois setores, o que reforça a definição de informalidade dada pelo autor, bem como permite fazer uma associação direta com a ideia do mercado de trabalho dual em moldes semelhantes ao proposto por Harris e Todaro (1970).

No modelo de Harris e Todaro (1970), a dualidade se dá em termos de emprego rural e urbano. Enquanto que o primeiro se caracteriza por um maior uso do fator trabalho, o segundo é caracterizado pelos trabalhadores industriais. Como nota Fields (1990), em tal modelo não há uma distinção interna aos trabalhadores urbanos, que consequentemente são considerados apenas como empregados no setor moderno, ou então desempregados. Entretanto, a evidência revelou que nas áreas urbanas das economias em desenvolvimento existem trabalhadores que não se enquadram em nenhuma dessas duas categorias. Tais trabalhadores se encontram em uma posição intermediária, por vezes denominada de subemprego, na qual, apesar de não estarem desempregados, seu trabalho não pode ser caracterizado dentro do setor moderno. É o que acabou tornando-se conhecido como o setor informal urbano.

Mais recentemente, a OIT (2002) estabelece que a característica fundamental dos grupos denominados informais é que os mesmos não são reconhecidos ou protegidos pelas instituições legais e regulatórias. Mas, além disso, o órgão ressalta outras características dos trabalhadores informais, como maior vulnerabilidade, ausência de proteção social e legal, in- 
capacidade de fazer cumprir contratos, incapacidade de se organizar para alcançar representatividade e limitação à capacidade de desfrutar de infraestrutura e benefícios públicos.

Outros autores e órgãos definem o mercado de trabalho informal por meio de outras características, mas mantendo a ideia fundamental de que o mesmo é composto por trabalhadores em situações desvantajosas em relação àqueles alocados no mercado formal. Em trabalho para o Banco Mundial, Almeida, Alves e Graham (1995) caracterizam o mercado formal como aquele em que ocorrem salários relativamente elevados, seguridade social, férias, pensões e seguridade do emprego, de acordo com a legislação. Aqueles indivíduos que não conseguem emprego em tal setor tendem a procurar a alternativa da informalidade, caracterizada em geral por pequenas empresas ou autoemprego, em que predominam atividades intensivas em trabalho e que não desfrutam de benefícios sociais.

No contexto brasileiro, Leone (2010) pontua que é a partir da Consolidação das Leis do Trabalho (CLT), em 1943, que são definidas as regras mínimas das relações trabalhistas, como o piso salarial, a jornada de trabalho, entre outros direitos. A garantia de tais direitos ao trabalhador significava que o mesmo poderia ser considerado formal.

Traduzindo as definições de informalidade para um contexto mais contemporâneo, Leone (2010) considera que os trabalhadores informais são aqueles privados de condições básicas de trabalho e proteção social, sendo caracterizados por indefinições dos locais de trabalho, baixos níveis de qualificação e produtividade, condições de trabalho sem segurança, entre outros. Para a autora, tal diversidade de condições desvantajosas ao trabalhador informal leva, em muitos casos, à utilização dos termos precariedade, subemprego e informalidade como sinônimos.

Em termos empíricos, convencionou-se mensurar e analisar a segmentação formal-informal por meio das diferenças de rendimento entre tais setores. Se, após controladas as características observáveis do trabalhador e dos postos de trabalho, persistem diferenças significativas de rendimento (geralmente a favor da formalidade), tem-se evidências de que a segmentação de fato ocorre para o caso em questão. Entre os diversos trabalhos nessa linha, pode-se mencionar Carneiro e Henley (2001), Tannuri-Pianto e Pianto (2002, 2016), Menezes Filho, Mendes e Almeida (2004), Ulyssea (2007), Machado, Oliveira e Antigo (2008), Botelho e Ponczek (2009) e Loureiro, Araújo e Souza (2013). 
Em geral, tais trabalhos confirmam a hipótese do mercado de trabalho segmentado, embora permaneçam certas lacunas, como as necessidades de avaliar a segmentação em diferentes partes da distribuição de rendimentos, sobretudo em quantis extremos; de investigar o fenômeno entre autônomos e empregadores; e de não ignorar o viés de seleção das mulheres no mercado de trabalho. Além disso, os trabalhos mencionados tendem a tratar a endogenia setorial com modelos de seleção, ao passo que a presente proposta é contornar esse problema com efeitos de tratamento endógenos, utilizando variáveis instrumentais. Tais aspectos metodológicos são explorados na quarta seção deste trabalho.

\section{Base de dados e análise descritiva das variáveis}

A presente seção compreende uma descrição da fonte de dados utilizada, os recortes realizados e as variáveis selecionadas. Além disso, apresenta-se uma análise descritiva das variáveis, a fim de providenciar a contextualização necessária para auxiliar na compreensão e interpretação dos resultados posteriormente obtidos por meio da aplicação do modelo de análise proposto.

\subsection{Fonte de dados, recorte e variáveis}

Os dados do presente trabalho foram retirados da Pesquisa Nacional por Amostra de Domicílios (PNAD) para os anos de 2002 e 2012, sendo a amostra utilizada constituída por homens entre 25 e 55 anos. A escolha de tal faixa etária se deu de modo a obter uma amostra de características mais homogêneas, evitando comparar indivíduos pertencentes a grupos muito diferentes, como trabalhadores jovens e aqueles próximos de se aposentar, que possuem dinâmicas mais peculiares no mercado de trabalho.

Como o foco é a comparação entre os setores, serão considerados exclusivamente os trabalhadores do sexo masculino, evitando-se eventuais distorções causadas pela discriminação de gênero e pelo problema de seletividade amostral da participação feminina no trabalho. Sobre este último aspecto, como a quase totalidade dos homens está no mercado de trabalho, tal problema é praticamente irrelevante quando se estimam suas 
equações de rendimentos, ao passo que, no que tange às mulheres, a seletividade amostral é reconhecidamente relevante. Em outros termos, é preciso considerar não apenas a seleção dos indivíduos entre os setores formal e informal, mas também a seleção das mulheres no mercado de trabalho. Essa questão é frequentemente ignorada na literatura nacional. ${ }^{6}$ No contexto quantílico, o tratamento para a seleção amostral envolve a aplicação da metodologia proposta por Buchinsky (1998), mas devido à indisponibilidade dos elevados recursos computacionais que a implementação do método demanda com amostras grandes, optou-se por restringir a presente análise apenas à força de trabalho masculina.

Ainda foram considerados apenas os trabalhadores urbanos, uma vez que suas características são consideravelmente distintas daqueles localizados no meio rural, especialmente em relação à previdência. Além disso, a PNAD só passou a incluir a área rural da região Norte a partir de 2004, o que comprometeria a consistência do recorte entre 2002 e 2012, caso não se optasse exclusivamente pelo meio urbano.

A presente análise se dá sobre dois grupos distintos. $\bigcirc$ primeiro, aqui denominado de empregados, abrange as posições de ocupação da PNAD que dizem respeito a empregados com carteira, outros empregados sem carteira, empregados sem declaração de carteira, trabalhador doméstico com carteira, trabalhador doméstico sem carteira e trabalhador doméstico sem declaração de carteira. O segundo é composto pelos trabalhadores por conta própria (autônomos) e empregadores.

O critério de formalidade, por sua vez, foi definido de acordo com os referidos grupos. Para os empregados, a formalidade é definida pela posse de carteira de trabalho assinada. Para autônomos e empregadores, o critério é a contribuição para a previdência.

Dadas as características selecionadas para o presente trabalho, a amostra utilizada em 2002 era composta por 49.072 indivíduos, sendo 18.103 classificados como trabalhadores autônomos e empregadores e 30.969 como empregados; enquanto que em 2012 a amostra foi de 51.112 indivíduos, dividida entre 16.034 autônomos e empregadores, e 35.078 empregados. A Tabela 1 apresenta as variáveis utilizadas neste estudo a fim de controlar

6 Como nos trabalhos de Carneiro e Henley (2001), Tannuri-Pianto e Pianto (2002, 2016), Machado, Oliveira e Antigo (2008), Botelho e Ponczek (2009), Loureiro, Araújo e Souza (2013). Uma exceção é o trabalho de Menezes Filho, Mendes e Almeida (2004), que também contorna o problema abordando apenas os trabalhadores masculinos. 
as diferenças de rendimentos para os atributos regionais dos indivíduos e de seus empregos.

As variáveis relacionadas à escolaridade e idade seguem a ideia da teoria do capital humano, desenvolvida inicialmente por Schultz (1961) e Becker (1962), em que tais fatores afetam positivamente os rendimentos, conforme modelo formulado por Mincer (1974). As demais variáveis, relacionadas às características dos indivíduos, às suas localidades e postos de trabalho, que não dizem respeito diretamente ao capital humano, são incluídas seguindo a sugestão de Borjas e Mincer (1976), e de diversos outros trabalhos que vão pela mesma linha, como Carneiro e Henley (2001), Tannuri-Pianto e Pianto (2002) e Machado, Oliveira e Antigo (2008).

\section{Tabela 1 Variáveis utilizadas}

\begin{tabular}{|c|c|}
\hline Variável & Descrição \\
\hline Rendimentos & $\begin{array}{l}\text { Rendimento mensal, em reais, que o trabalhador recebia em seu trabalho principal } \\
\text { na semana de referência. Os rendimentos de } 2002 \text { foram corrigidos para setembro de } \\
2012 \text { pelo deflator de rendimentos da PNAD proposto por Corseuil e Foguel (2002). }\end{array}$ \\
\hline$E_{k}$ & $\begin{array}{l}\text { Dummies que indicam o nível educacional, com } \mathrm{k}=1, \ldots, 4 \text {, em que o grupo base é } \\
\text { formado por aqueles sem nenhum ano de estudo e: } \\
\text { - E1: assume valor } 1 \text { para } 1 \text { a } 3 \text { anos de estudo, e } 0 \text { caso contrário. } \\
\text { - E2: assume valor } 1 \text { para } 4 \text { a } 7 \text { anos de estudo, e } 0 \text { caso contrário. } \\
\text { - E3: assume valor } 1 \text { para } 8 \text { a } 10 \text { anos de estudo, e } 0 \text { caso contrário. } \\
\text { - E4: assume valor } 1 \text { para } 10 \text { a } 14 \text { anos de estudo, e } 0 \text { caso contrário. } \\
\text { - E5: assume valor } 1 \text { para } 15 \text { ou mais anos de estudo, e } 0 \text { caso contrário. }\end{array}$ \\
\hline I & Variável discreta indicando a idade do trabalhador ( proxy para a experiência) \\
\hline $\mathrm{R}_{\mathrm{m}}$ & $\begin{array}{l}\text { Dummies raciais, com m =1,2, em que o grupo base são indivíduos não-negros e: } \\
\text { - R1: assume valor } 1 \text { para indivíduos pretos e } 0 \text { caso contrário. } \\
\text { - R2: assume valor } 1 \text { para indivíduos pardos e } 0 \text { caso contrário. }\end{array}$ \\
\hline RM & $\begin{array}{l}\text { Dummy com valor } 1 \text { para indivíduo com domicílio em região metropolitana e } 0 \text { caso } \\
\text { contrário. }\end{array}$ \\
\hline $\operatorname{Reg}_{\mathrm{n}}$ & $\begin{array}{l}\text { Dummies regionais, com } n=1, \ldots, 4 \text {, em que o grupo base é o Nordeste e: } \\
\text { - Reg1: assume valor } 1 \text { para a região Sudeste e } 0 \text { caso contrário. } \\
\text { - Reg2: assume valor } 1 \text { para a região Sul e } 0 \text { caso contrário. } \\
\text { - Reg3: assume valor } 1 \text { para a região Centro-Oeste e } 0 \text { caso contrário. } \\
\text { - Reg4: assume valor } 1 \text { para a região Norte e } 0 \text { caso contrário. }\end{array}$ \\
\hline $\mathrm{S}_{\mathrm{k}}$ & $\begin{array}{l}\text { Dummies setoriais, com } \mathrm{k}=1, \ldots, 4, \text { em que o grupo base é a indústria e: } \\
\text { - S1: assume valor } 1 \text { para a construção e } 0 \text { caso contrário. } \\
\text { - S2: assume valor } 1 \text { para o comércio e } 0 \text { caso contrário. } \\
\text { - S3: assume valor } 1 \text { para os serviços e } 0 \text { caso contrário. }\end{array}$ \\
\hline
\end{tabular}


Tabela 1 (continuação)

\begin{tabular}{|c|c|}
\hline Variável & Descrição \\
\hline $0_{m}$ & $\begin{array}{l}\text { Dummies para grupos ocupacionais, com } m=1, \ldots, 6, \text { em que: } \\
\text { - 01: dirigentes em geral. } \\
\text { - 02: profissionais das ciências e das artes. } \\
\text { - 03: técnicos de nível médio. } \\
\text { - 04: trabalhadores de serviços administrativos. } \\
\text { - 05: trabalhadores dos serviços. } \\
\text { - 06: vendedores e prestadores de serviço do comércio. } \\
\text { Sendo o grupo base formado pelos trabalhadores nos demais grupos ocupacionais. }\end{array}$ \\
\hline $\begin{array}{l}\text { Emprego } \\
\text { anterior }\end{array}$ & $\begin{array}{l}\text { Dummy que assume valor } 1 \text { caso o indivíduo possuísse emprego anterior no perío- } \\
\text { do de um ano, e } 0 \text { caso contrário. }\end{array}$ \\
\hline $\begin{array}{l}\text { Anos no } \\
\text { emprego atual }\end{array}$ & $\begin{array}{l}\text { Variável continua indicando a quantidade de anos que o trabalhador estava em seu } \\
\text { atual emprego. }\end{array}$ \\
\hline Empregadores & $\begin{array}{l}\text { Dummy que assume valor } 1 \text { caso o indivíduo fosse empregador, e } 0 \text { caso contrário } \\
\text { (utilizada apenas entre autônomos e empregadores). }\end{array}$ \\
\hline Domésticos & $\begin{array}{l}\text { Dummy que assume valor } 1 \text { caso o indivíduo fosse trabalhador doméstico, e } 0 \text { caso } \\
\text { contrário (utilizada apenas entre empregados). }\end{array}$ \\
\hline
\end{tabular}

Fonte: Elaboração própria.

\subsection{Análise descritiva das variáveis}

As Tabelas 2 a 4 apresentam as informações amostrais e as médias de renda, escolaridade e idade para os trabalhadores formais e informais dentro de cada grupo, bem como as respectivas proporções dos atributos raciais, geográficos e setoriais para 2002 e 2012.

Inicialmente, nota-se que o grupo composto por trabalhadores por conta própria e empregadores $(\mathrm{CP} \& \mathrm{E})$ possui rendimentos médios mais elevados que os empregados, sendo que a razão entre ambos permanece estável entre os anos, com a vantagem do primeiro grupo sendo da ordem de $36,48 \% \mathrm{em}$ 2002 e de $36,24 \%$ em 2012. Além disso, autônomos e empregadores tendem a ser menos escolarizados e mais velhos que os empregados, sugerindo uma possível compensação, em termos de capital humano, de um atributo pelo outro, uma vez que a idade é proxy da experiência. Contudo, o gap educacional entre esses grupos diminuiu no período, de uma diferença de $19,48 \%$ em favor dos empregados em 2002, para 8,84\% em 2012. Já no que tange à idade, o diferencial permaneceu relativamente estável, com vantagem de 9\% para empregadores e conta própria em 2002, e 9,27\% em 2012. 
Tabela 2 Informações gerais das amostras de 2002 e 2012

\begin{tabular}{lrrrr|r|r}
\hline Variável & \multicolumn{2}{|c}{ 2002 } & \multicolumn{2}{r}{ 2012 } \\
\cline { 2 - 7 } & Geral & CP\&E & Empreg. & Geral & CP\&E & Empreg. \\
\hline Rendimento (R\$) & 1590,40 & 1915,78 & 1403,71 & 1812,11 & 2220,18 & 1629,65 \\
\hline Escolaridade (anos) & 7,22 & 7,03 & 7,34 & 8,77 & 8,26 & 8,99 \\
\hline Idade (anos) & 37,83 & 39,93 & 36,63 & 38,38 & 40,77 & 37,31 \\
\hline Pretos & $6,36 \%$ & $5,42 \%$ & $6,89 \%$ & $9,56 \%$ & $7,94 \%$ & $10,28 \%$ \\
\hline Pardos & $37,33 \%$ & $36,95 \%$ & $37,54 \%$ & $43,01 \%$ & $43,64 \%$ & $42,73 \%$ \\
\hline Brancos ${ }^{2}$ & $56,32 \%$ & $57,63 \%$ & $55,57 \%$ & $47,43 \%$ & $48,43 \%$ & $46,99 \%$ \\
\hline Sudeste & $49,63 \%$ & $45,45 \%$ & $52,03 \%$ & $47,83 \%$ & $42,77 \%$ & $50,09 \%$ \\
\hline Sul & $15,83 \%$ & $15,53 \%$ & $16,01 \%$ & $15,17 \%$ & $15,38 \%$ & $15,07 \%$ \\
\hline Centro-0este & $7,69 \%$ & $7,90 \%$ & $7,57 \%$ & $8,48 \%$ & $8,83 \%$ & $8,32 \%$ \\
\hline Norte & $5,98 \%$ & $7,17 \%$ & $5,30 \%$ & $6,91 \%$ & $8,50 \%$ & $6,19 \%$ \\
\hline Nordeste & $20,87 \%$ & $23,96 \%$ & $19,10 \%$ & $21,62 \%$ & $24,51 \%$ & $20,33 \%$ \\
\hline Agricultura & $7,39 \%$ & $7,55 \%$ & $7,30 \%$ & $5,66 \%$ & $6,14 \%$ & $5,45 \%$ \\
\hline Construção & $15,89 \%$ & $23,53 \%$ & $11,50 \%$ & $18,03 \%$ & $29,29 \%$ & $13,00 \%$ \\
\hline Comércio & $22,40 \%$ & $30,82 \%$ & $17,57 \%$ & $20,90 \%$ & $26,45 \%$ & $18,41 \%$ \\
\hline Serviços & $33,92 \%$ & $27,84 \%$ & $37,40 \%$ & $36,53 \%$ & $30,64 \%$ & $39,17 \%$ \\
\hline Indústria & $20,40 \%$ & $10,26 \%$ & $26,22 \%$ & $18,87 \%$ & $7,48 \%$ & $23,97 \%$ \\
\hline Reg. metrop. & $36,94 \%$ & $33,64 \%$ & $38,83 \%$ & $36,43 \%$ & $31,45 \%$ & $38,66 \%$ \\
\hline Reg. não metrop. & $63,06 \%$ & $66,36 \%$ & $61,17 \%$ & $63,57 \%$ & $68,55 \%$ & $61,34 \%$ \\
\hline Formais ${ }^{3}$ & $52,66 \%$ & $26,43 \%$ & $67,99 \%$ & $64,30 \%$ & $34,97 \%$ & $77,70 \%$ \\
\hline Informais ${ }^{3}$ & $47,34 \%$ & $73,57 \%$ & $32,01 \%$ & $35,70 \%$ & $65,03 \%$ & $22,30 \%$ \\
\hline No de observações & 49072 & 18103 & 30969 & 51112 & 16034 & 35078 \\
\hline
\end{tabular}

Fonte: Elaboração própria, com base em dados das PNADS de 2002 e 2012.

Obs: Todos os valores foram obtidos considerando os pesos de amostra complexa das PNADS.

1: Valores em reais de setembro de 2012.

2: O recorte de "brancos" abrange todos os não negros.

3: 0 critério de formalidade para empregadores e trabalhadores por conta própria é a contribuição para previdência, enquanto que para os empregados é a carteira de trabalho.

No que tange aos atributos raciais, pretos e pardos tendem a ser proporcionalmente mais representados no segmento dos empregados, sendo que a participação dos pretos em tal grupo é inclusive maior do que a sua proporção na população nacional, especialmente no ano de $2012{ }^{7}$ Em termos regionais, o Sudeste tende a ser a região populacionalmente 7 Segundo o IBGE (2012a), em 2000 os pretos representavam 6,2\% da população brasileira, enquanto que em 2010 eram 7,6\%. 
mais sobrerrepresentada em ambos os grupos, enquanto que o Nordeste é a mais sub-representada. ${ }^{8}$ Essas diferenças são mais intensas para os empregados do que para os empregadores e conta própria, e sugerem um caráter regional do fenômeno que se associa com o nível de desenvolvimento econômico.

Tabela 3 Médias e proporções dos atributos dos trabalhadores formais e informais homens, segundo suas características - 2002

\begin{tabular}{lrrrrr}
\hline \multirow{2}{*}{ Variável } & Empregadores e Conta Própria & & Empregados \\
\cline { 2 - 5 } & Formais $^{\mathbf{3}}$ & Informais $^{\mathbf{3}}$ & Formais $^{\mathbf{3}}$ & Informais $^{\mathbf{3}}$ \\
\hline Rendimento (R\$) & 3513,01 & 1256,40 & 1586,22 & 988,09 \\
\hline Escolaridade (anos) & 9,65 & 5,95 & 7,90 & 6,06 \\
\hline Idade (anos) & 41,36 & 39,33 & 36,69 & 36,50 \\
\hline Pretos & $3,14 \%$ & $6,36 \%$ & $6,76 \%$ & $7,19 \%$ \\
\hline Pardos & $20,03 \%$ & $43,94 \%$ & $34,12 \%$ & $45,32 \%$ \\
\hline Brancos ${ }^{2}$ & $76,83 \%$ & $49,70 \%$ & $59,11 \%$ & $47,49 \%$ \\
\hline Sudeste & $59,40 \%$ & $39,68 \%$ & $56,62 \%$ & $41,55 \%$ \\
\hline Sul & $20,86 \%$ & $13,33 \%$ & $17,22 \%$ & $13,25 \%$ \\
\hline Centro-0este & $6,35 \%$ & $8,54 \%$ & $6,84 \%$ & $9,24 \%$ \\
\hline Norte & $2,64 \%$ & $9,04 \%$ & $4,06 \%$ & $8,12 \%$ \\
\hline Nordeste & $10,74 \%$ & $29,41 \%$ & $15,26 \%$ & $27,84 \%$ \\
\hline Agricultura & $3,49 \%$ & $9,22 \%$ & $3,78 \%$ & $15,33 \%$ \\
\hline Construção & $11,09 \%$ & $28,67 \%$ & $8,46 \%$ & $18,44 \%$ \\
\hline Comércio & $36,54 \%$ & $28,46 \%$ & $17,48 \%$ & $17,78 \%$ \\
\hline Serviços & $36,79 \%$ & $24,15 \%$ & $38,32 \%$ & $35,31 \%$ \\
\hline Indústria & $12,09 \%$ & $9,50 \%$ & $31,96 \%$ & $13,15 \%$ \\
\hline Reg. metrop. & $36,79 \%$ & $32,34 \%$ & $42,04 \%$ & $31,52 \%$ \\
\hline Reg. não metrop. & $63,21 \%$ & $67,66 \%$ & $57,96 \%$ & $68,48 \%$ \\
\hline No de observações & 4784 & 13319 & 21056 & 9913 \\
\hline
\end{tabular}

Fonte: Elaboração própria, com base em dados das PNADS de 2002 e 2012.

1: Valores em reais de setembro de 2012.

2: O recorte de "brancos" abrange todos os não negros.

3: 0 critério de formalidade para empregadores e trabalhadores por conta própria é a contribuição para previdência, enquanto que para os empregados é a carteira de trabalho.

8 De acordo com dados do Censo de 2010, em tal ano as populações do Sudeste e do Nordeste representavam, respectivamente, $42,13 \%$ e $27,83 \%$ da população nacional (IBGE, 2012b). 
Setorialmente, a indústria e os serviços possuem os maiores contingentes de empregados, enquanto que trabalhadores por conta própria e empregadores são preponderantes no comércio, seguido por serviços e construção. As diferenças proporcionais mais significativas entre os dois grupos ocorrem na construção, que é cerca de duas vezes maior entre empregadores e conta própria, e na indústria, cerca de três vezes superior entre empregados. Também é possível perceber que estes são proporcionalmente mais presentes nas regiões metropolitanas, enquanto que nas regiões não metropolitanas o peso dos autônomos e empregadores é relativamente maior do que nas metrópoles.

Ainda, nota-se um predomínio da informalidade entre empregadores e autônomos (cujo critério é a contribuição para previdência), enquanto que entre empregados prevalece a formalidade (definida pela carteira de trabalho assinada). Contudo, ambos os grupos verificaram um considerável aumento da formalização no período em questão, de modo que entre trabalhadores por conta própria e empregadores ela passa aproximadamente de uma proporção de um quarto para um terço, ao passo que para os empregados a formalidade passa de cerca de dois terços para pouco mais de três quartos. Considerando a amostra como um todo, a formalização passa de pouco mais da metade dos trabalhadores para quase dois terços.

Tabela 4 Médias e proporções dos atributos dos trabalhadores formais e informais homens, segundo suas características - 2012

\begin{tabular}{lrrrrr}
\hline \multirow{2}{*}{ Variável } & Empregadores e Conta Própria & & Empregados \\
\cline { 2 - 5 } & Formais $^{\mathbf{3}}$ & Informais $^{\mathbf{3}}$ & Formais $^{\mathbf{3}}$ & Informais $^{\mathbf{3}}$ \\
\hline Rendimento (R\$) & 3442,58 & 1488,65 & 1726,45 & 1275,36 \\
\hline Escolaridade (anos) & 10,02 & 7,21 & 9,38 & 7,58 \\
\hline Idade (anos) & 41,78 & 40,16 & 37,27 & 37,47 \\
\hline Pretos & $5,83 \%$ & $9,20 \%$ & $10,15 \%$ & $10,77 \%$ \\
\hline Pardos & $31,27 \%$ & $51,04 \%$ & $40,65 \%$ & $50,36 \%$ \\
\hline Brancos ${ }^{2}$ & $62,91 \%$ & $39,76 \%$ & $49,20 \%$ & $38,87 \%$ \\
\hline Sudeste & $51,03 \%$ & $37,83 \%$ & $53,36 \%$ & $38,09 \%$ \\
\hline Sul & $21,88 \%$ & $11,49 \%$ & $16,22 \%$ & $10,87 \%$ \\
\hline Centro-0este & $8,82 \%$ & $8,84 \%$ & $8,13 \%$ & $8,99 \%$ \\
\hline Norte & $3,66 \%$ & $11,40 \%$ & $5,10 \%$ & $10,18 \%$ \\
\hline Nordeste & $14,62 \%$ & $30,44 \%$ & $17,18 \%$ & $31,86 \%$ \\
\hline & & & & $($ continua)
\end{tabular}


Tabela 4 (continuação)

\begin{tabular}{l|rr|r|r}
\hline \multirow{2}{*}{ Variável } & Empregadores e Conta Própria & & Empregados $^{\text {Enyyy }}$ \\
\cline { 2 - 5 } & Formais $^{\mathbf{3}}$ & Informais $^{\mathbf{3}}$ & Formais $^{\mathbf{3}}$ & Informais $^{\mathbf{3}}$ \\
\hline Agricultura & $4,67 \%$ & $7,02 \%$ & $3,70 \%$ & $11,85 \%$ \\
\hline Construção & $15,97 \%$ & $37,26 \%$ & $10,71 \%$ & $21,40 \%$ \\
\hline Comércio & $32,08 \%$ & $23,09 \%$ & $18,81 \%$ & $16,96 \%$ \\
\hline Serviços & $37,82 \%$ & $26,35 \%$ & $38,95 \%$ & $39,98 \%$ \\
\hline Indústria & $9,47 \%$ & $6,28 \%$ & $27,83 \%$ & $9,81 \%$ \\
\hline Reg. metrop. & $31,63 \%$ & $31,34 \%$ & $41,18 \%$ & $29,45 \%$ \\
\hline Reg. não metrop. & $68,37 \%$ & $68,66 \%$ & $58,82 \%$ & $70,55 \%$ \\
\hline $\mathbf{N}^{\mathbf{0}}$ de observações & 5607 & 10427 & 27256 & 7822 \\
\hline
\end{tabular}

Fonte: Elaboração própria, com base em dados das PNADS de 2002 e 2012.

1: Valores em reais de setembro de 2012.

2: O recorte de "brancos" abrange todos os não negros.

3: 0 critério de formalidade para empregadores e trabalhadores por conta própria é a contribuição para previdência, enquanto que para os empregados é a carteira de trabalho.

Ao comparar formais e informais em ambos os grupos, visualiza-se em primeiro lugar uma diferença média de rendimentos em favor dos trabalhadores formais, que é mais intensa entre autônomos e empregadores, mas que se atenua no período para os dois grupos. Enquanto em 2002 os empregadores e trabalhadores por conta própria que contribuíam para previdência (formais) possuíam rendimentos 2,8 vezes maiores que aqueles que não contribuíam (informais), em 2012 essa diferença era de 2,3 vezes. Para os empregados, a diferença entre aqueles com carteira (formais) para os sem carteira (informais) passou de 1,6 vezes em 2002 para 1,35 vezes em 2012. Em termos gerais, observa-se, portanto, que não apenas aumentou a formalização geral do mercado de trabalho brasileiro como reduziu-se a disparidade entre formais e informais - o que equivale a dizer que os trabalhadores informais observaram ganhos médios proporcionalmente maiores no período. Contudo, tal diferencial é em termos brutos, e desconsidera os atributos dos trabalhadores, de seus postos de trabalho e de seus contextos regionais.

Simultaneamente, ocorreu um estreitamento do diferencial de escolaridade média que, embora tenha aumentado para todos os grupos, teve maiores incrementos entre os informais. Entre trabalhadores por conta própria e empregadores, a razão de escolaridade entre formais e informais reduziu-se de 1,6 para 1,4 no período, enquanto que para os empregados a 
redução foi de 1,3 para 1,2. Comportamento similar ocorreu para a idade, inclusive com os empregados informais tornando-se ligeiramente mais velhos, em média, do que os formais em 2012.

A formalidade é mais preponderante racialmente entre brancos (não-negros), sobretudo no caso dos empregadores e autônomos, com alguma atenuação dessa vantagem entre os anos. Em termos regionais, o Sudeste tende a ser mais formalizado, ao passo que no Nordeste a informalidade é relativamente mais predominante. Tal quadro não sofreu mudanças substanciais ao longo dos anos considerados.

Tabela 5 Proporção de formais e informais nas amostras, segundo quantis dos rendimentos

\begin{tabular}{|c|c|c|c|c|}
\hline \multirow[t]{2}{*}{ Variável } & \multicolumn{2}{|c|}{ Empregadores e Conta Própria } & \multicolumn{2}{|r|}{ Empregados } \\
\hline & Formais $^{1}$ & Informais ${ }^{1}$ & Formais $^{1}$ & Informais ${ }^{1}$ \\
\hline \multicolumn{5}{|l|}{2002} \\
\hline Q1-Q10 & $2,87 \%$ & $97,13 \%$ & $22,03 \%$ & $77,97 \%$ \\
\hline Q11-Q25 & $5,82 \%$ & $94,18 \%$ & $57,34 \%$ & $42,66 \%$ \\
\hline Q26-Q50 & $12,86 \%$ & $87,14 \%$ & $69,97 \%$ & $30,03 \%$ \\
\hline Q51-Q75 & $29,61 \%$ & $70,39 \%$ & $79,12 \%$ & $20,88 \%$ \\
\hline Q76-Q90 & $51,69 \%$ & $48,31 \%$ & $79,74 \%$ & $20,26 \%$ \\
\hline Q91-Q100 & $68,95 \%$ & $31,05 \%$ & $79,53 \%$ & $20,47 \%$ \\
\hline $\mathrm{N}^{0}$ de observações & 4784 & 13319 & 21056 & 9913 \\
\hline \multicolumn{5}{|l|}{2012} \\
\hline Q1-Q10 & $7,24 \%$ & $92,76 \%$ & $36,04 \%$ & $63,96 \%$ \\
\hline Q11-Q25 & $15,47 \%$ & $84,53 \%$ & $74,69 \%$ & $25,31 \%$ \\
\hline Q26-Q50 & $22,75 \%$ & $77,25 \%$ & $81,22 \%$ & $18,78 \%$ \\
\hline Q51-Q75 & $40,31 \%$ & $59,69 \%$ & $86,21 \%$ & $13,79 \%$ \\
\hline Q76-Q90 & $60,08 \%$ & $39,92 \%$ & $84,91 \%$ & $15,09 \%$ \\
\hline Q91-Q100 & $71,49 \%$ & $28,51 \%$ & $82,98 \%$ & $17,02 \%$ \\
\hline $\mathrm{N}^{0}$ de observações & 5607 & 10427 & 27256 & 7822 \\
\hline
\end{tabular}

Fonte: Elaboração própria, com base em dados das PNADS de 2002 e 2012.

1: 0 critério de formalidade para empregadores e trabalhadores por conta própria é a contribuição para previdência, enquanto que para os empregados é a carteira de trabalho.

A Tabela 5 apresenta a distribuição amostral de formais e informais, segundo os critérios respectivos a cada categoria, para diferentes intervalos de quantis da distribuição de rendimentos. Observa-se que a informalida- 
de predomina nos quantis iniciais, isto é, entre os trabalhadores de menor rendimento, tanto entre empregados quanto entre trabalhadores por conta própria e empregadores. Tal predomínio é mais intenso entre este último grupo, em que a quase totalidade dos indivíduos encontra-se na informalidade (não contribuindo para a previdência) até a mediana da distribuição de rendimentos.

A taxa de formalização cresce à medida que os rendimentos aumentam, de modo que no topo da distribuição dos rendimentos a proporção de trabalhadores formais entre empregadores e trabalhadores por conta própria já é relativamente próxima da proporção verificada entre empregados. Ainda, nota-se que a formalidade aumentou para todos os segmentos de renda entre os anos em questão, especialmente entre empregados na cauda inferior da distribuição.

\section{Efeito de tratamento quantílico dos rendimentos dos trabalhadores formais e informais}

Frequentemente é do interesse das ciências econômicas avaliar o impacto de alguma intervenção ou política pública sobre um determinado produto. A mensuração de tais impactos é comumente realizada por meio de métodos de efeito de tratamento, que permitem comparar o resultado observado por um grupo que sofreu uma determinada intervenção (ou tratamento) a um grupo de controle, que não recebeu o tratamento. Essa comparação é possibilitada com a construção de contrafactuais, que visam revelar qual teria sido o resultado de uma determinada observação tratada da amostra caso ela não tivesse recebido o tratamento, ou vice-versa.

No caso da avaliação do impacto da formalidade sobre os rendimentos dos trabalhadores, a formalização pode ser considerada o tratamento cujo impacto se almeja mensurar, enquanto que o grupo de controle é formado pelos indivíduos não-formais. No entanto, duas dificuldades se impõem nesse cenário. A primeira diz respeito à importância de se levar em consideração a distribuição dos rendimentos, e não apenas sua média. A formalização possivelmente apresenta impactos heterogêneos sobre os diferentes grupos de rendimentos, de modo que uma avaliação apenas em termos médios tem pouco a informar a respeito dos trabalhadores no topo 
ou na base da distribuição de renda, por exemplo. A segunda se refere ao fato de que o tratamento, neste caso, não pode ser considerado exógeno, algo que fere os requerimentos de métodos tradicionais de efeito de tratamento. Como em muitos casos é razoável assumir que o indivíduo se autosseleciona ${ }^{9}$ dentro do mercado formal ou informal, a estimação torna-se viesada, uma vez que não é possível distinguir os impactos da escolha individual dos efeitos puros do tratamento.

Para responder a essas dificuldades, utiliza-se aqui um método de efeito de tratamento quantílico sob endogeneidade proposto por Frölich e Melly (2008). Tal método permite verificar os impactos do tratamento sobre os diferentes quantis da distribuição do resultado, bem como possibilita superar o problema da endogeneidade por meio da utilização de variável instrumental para o tratamento. Ainda, o método proposto é de caráter não-condicional, isto é, os efeitos de tratamento não são condicionados às covariadas, sendo uma função unidimensional dos quantis. Não obstante, a inclusão das covariadas é importante para o método, pois permite a identificação do impacto indireto do instrumento na variável dependente. Uma explicação detalhada sobre o método é apresentada no Apêndice 1. A seguir, apresenta-se a escolha dos instrumentos e os resultados obtidos pela aplicação do método para empregados e trabalhadores por conta própria em conjunto com empregadores.

\subsection{Escolha dos instrumentos}

Como a variável de tratamento é binária, assumindo o valor 1 no caso do trabalhador ser formal (e portanto tratado), e zero caso contrário (informal e, portanto, não tratado), requer-se que a variável instrumental também seja binária. Esse tipo de restrição tende a dificultar ainda mais a seleção de instrumentos bons e válidos, isto é, que possuam a maior correlação possível com a variável instrumentalizada, e que não se correlacionem com o erro da equação de interesse.

A primeira etapa na seleção dos instrumentos consistiu em selecioná-los com base em uma justificativa plausível do ponto de vista teórico e lógico para posteriormente testar suas correlações com as variáveis de tra-

9 Ver, por exemplo, Maloney (1999), e a revisão de literatura feita por Ulyssea (2006). 
tamento. Como os critérios de formalidade são diferentes entre os grupos, procurou-se por instrumentos diferentes para cada um.

No caso da formalidade dos empregados, cujo critério é a carteira de trabalho, o instrumento selecionado foi o tempo de deslocamento para o trabalho. Criou-se, para tanto, uma variável binária assumindo valor 1 caso tal deslocamento fosse superior a 30 minutos. A justificativa para a escolha desse instrumento encontra-se em três fatores. $O$ primeiro diz respeito ao caráter metropolitano da formalidade dos empregados, uma vez que se observa (como apresentado na análise descritiva) que as regiões metropolitanas tendem a apresentar uma participação de empregados com carteira assinada cerca de dez a doze pontos percentuais maior do que as regiões não metropolitanas. Esse caráter provavelmente se replica na comparação entre cidades não-metropolitanas de grande porte em relação às cidades menores, de onde se deduz que tempos maiores de deslocamento tendem a estar mais associados com ambientes urbanos de maior dimensão, onde a formalização também tende a ser maior.

O segundo fator ancora-se na hipótese de que trabalhadores informais, especialmente os de menor renda, geralmente não contam com auxílios para deslocamento, tradicionalmente concedidos nos meios formais e que facilitam com que o trabalhador arque com custos de transporte mais longos. $\bigcirc$ terceiro fator se refere à possibilidade de que o emprego informal seja mais relacionado aos empregos familiares, em que o indivíduo trabalha num pequeno negócio da família - muitas vezes próximo à sua residência, ou mesmo conjugado com ela. Por fim, ressalta-se que, apesar de ser possível que tal instrumento também expresse em parte uma possível escolha do trabalhador (que pode preferir trabalhos mais próximos a sua residência), considera-se que tal escolha tenha um caráter mais exógeno, dada a restrição para o trabalhador de mudar ou escolher livremente a localidade de sua habitação no curto prazo, bem como seja mais provável que o mesmo não restrinja sua procura por trabalho a um pequeno raio a partir de seu local de habitação.

Para os trabalhadores por conta própria e empregadores, o instrumento foi construído com base em duas variáveis: a presença de sócio e mais de dez empregados no empreendimento. Nesses casos, a variável instrumental para o tratamento assume valor 1 . Tal escolha é justificada por se considerar mais provável que trabalhadores por conta própria e empregadores que possuem empreendimentos maiores (comportando mais funcionários, 
ou sócios) contribuam para a previdência, uma vez que tendem a ter mais condições para tanto. Como o tamanho do empreendimento nesses termos é uma decisão mais relacionada ao médio e longo prazo, considera-se que esse instrumento seja exógeno para a análise em questão.

De forma a analisar a adequabilidade estatística dos instrumentos selecionados, quatro etapas foram realizadas: i) calculou-se a correlação simples entre cada instrumento e a variável instrumentada; ii) realizou-se uma regressão logística da variável de tratamento contra o instrumento, em conjunto com demais variáveis relevantes; iii) testou-se formalmente a adequabilidade dos instrumentos por meio de estatísticas próprias para tanto, aplicadas num contexto de regressão de variáveis instrumentais em que a variável dependente era os rendimentos; e iv) gerou-se um variável binária aleatória para realizar um teste de falsificação com as etapas anteriores.

Os resultados obtidos das etapas acima são apresentados com detalhes no Apêndice 2, e apontam que os instrumentos são estatisticamente válidos. Em 2002, a correlação simples entre a formalidade pela previdência e seu instrumento (a presença de sócios ou empreendimentos com mais de dez funcionários) foi de 0,28 , enquanto que o coeficiente obtido da regressão logística foi de 0,68 , e significativo ao nível de $1 \%$. O teste de endogeneidade aponta que as diferenças do estimador de variável instrumental em relação aos mínimos quadrados ordinários (MOO) são estatisticamente significativas, rejeitando a hipótese nula de que a variável de tratamento seja exógena, condição sob a qual o estimador de $\mathrm{MOO}$ seria consistente e preferível. $\mathrm{O}$ teste de identificação fraca (estatística $F$ de Kleibergen-Paap) rejeita a hipótese nula de que o instrumento é fracamente correlacionado com a variável instrumentada. Por se tratar de um caso de identificação exata (número de instrumentos igual ao de variáveis instrumentadas), testes de correlação do instrumento com o erro não são possíveis.

Já em 2012, a correlação entre a formalidade pela previdência e o instrumento foi de 0,25 , e o coeficiente do logit de 0,7 . Os demais testes apresentaram os mesmos resultados que os verificados para 2002, isto é, rejeitam a hipótese de exogeneidade da variável de tratamento e também a identificação fraca.

Tais resultados também se repetem para o caso da formalidade pela carteira de trabalho, instrumentalizada pelo tempo de deslocamento até 
o trabalho, alterando-se apenas os coeficientes de correlação entre ambos, que são menores: em 2002, a correlação foi de 0,09 , ao passo que o coeficiente do instrumento na regressão logística foi de 0,51; em 2012, a correlação foi de 0,12, e o coeficiente do logit de 0,69. Em ambas as regressões, os coeficientes foram significativos ao nível de $1 \%$.

Por fim, a título de falsificação desses testes, para cada ano gerou-se uma variável binária aleatória, que foi utilizada para realizar as mesmas etapas acima no lugar dos instrumentos. Todas as correlações foram bastante baixas $(-0,0083$ e 0,003 para a informalidade pela previdência, e 0,0044 e -0,0002 para a formalidade pela carteira, para 2002 e 2012, respectivamente), bem como os valores dos parâmetros estimados pela regressão logística, que em todos os casos foram não significativos. Os testes de identificação fraca falharam em rejeitar a hipótese nula, de modo que nos quatro cenários a variável aleatória não pôde ser considerada como um bom instrumento.

Tomando os resultados acima, os instrumentos foram considerados válidos e adequados para prosseguir com a análise proposta. Embora os testes digam respeito a um contexto de regressão de variáveis instrumentais, que difere do exercício realizado na etapa a seguir, considera-se que as exigências dos instrumentos sejam as mesmas, e que os testes acima possibilitem uma aproximação bastante razoável a respeito da adequação dos mesmos ao método de efeitos de tratamento quantílicos.

\subsection{Resultados: evidências de segmentação formal-informal}

Selecionados os instrumentos, procedeu-se com a estimação dos efeitos de tratamento sobre todos os quantis da distribuição dos rendimentos logaritmizados. A Tabela 6 apresenta os resultados obtidos com o estimador de Frölich e Melly (2008) para quantis selecionados, resumindo a evolução dos diferenciais ao longo da distribuição de rendimentos. Dado que os efeitos de tratamento dizem respeito às diferenças "puras" entre os produtos observados, isto é, descontados os impactos de covariadas observáveis que expliquem a parcela da diferença bruta já observada na seção 3 , tem-se que as medidas obtidas fornecem indícios para a ocorrência de segmentação formal-informal no mercado de trabalho. Em outros termos, as diferenças mensuradas dizem respeito ao impacto direto do tratamento, 
isto é, da formalização. ${ }^{10}$ Faz-se a ressalva, contudo, de que uma possível segmentação apresenta caráter distinto entre os dois grupos analisados: enquanto que no caso dos trabalhadores é possível se falar em restrições no número de postos de trabalho formais disponíveis, para os autônomos e empregadores o mesmo não pode ser dito, visto que o acesso à contribuição para a previdência pode ser limitado apenas em função das restrições financeiras dos indivíduos.

Em geral, as maiores diferenças estimadas tendem a estar na base dos rendimentos, tanto para empregadores e autônomos quanto para empregados. No caso do primeiro grupo, em todos os quantis as diferenças entre formais e informais são mais intensas do que aquelas observadas no caso dos empregados. Além disso, essas diferenças tendem a sofrer alguma queda inicial, mantendo-se razoavelmente estáveis no restante da distribuição e voltando a crescer no topo, especialmente em 2012, quando a segmentação nessa parte da distribuição era mais intensa do que na base.

Tabela 6 Efeitos de tratamento para a formalidade sobre o logaritmo dos rendimentos - quantis selecionados

\begin{tabular}{|c|c|c|c|c|}
\hline \multirow[t]{2}{*}{ Quantil } & \multicolumn{2}{|r|}{2002} & \multicolumn{2}{|r|}{2012} \\
\hline & CP\&E & Empregados & CP\&E & Empregados \\
\hline \multirow[t]{2}{*}{ Quantil .01 } & $* * * 2,6554$ & $* * * 1,9148$ & $* * * 2,8538$ & $* * * 1,9315$ \\
\hline & $(0,2380)$ & $(0,1837)$ & $(0,4202)$ & $(0,1046)$ \\
\hline \multirow[t]{2}{*}{ Quantil .10 } & $* * * 1,4271$ & $* * * 1,0391$ & $* * * 1,9284$ & $* * * 0,6974$ \\
\hline & $(0,4201)$ & $(0,1845)$ & $(0,2059)$ & $(0,0972)$ \\
\hline \multirow[t]{2}{*}{ Quantil .20 } & $* * * 1,7758$ & $* * * 0,7491$ & $* * * 1,6650$ & $* * * 0,4877$ \\
\hline & $(0,4307)$ & $(0,1614)$ & $(0,2000)$ & $(0,0728)$ \\
\hline \multirow[t]{2}{*}{ Quantil.30 } & $* * * 1,5135$ & $* * * 0,6906$ & $* * * 1,6557$ & $* * * 0,3127$ \\
\hline & $(0,3321)$ & $(0,0560)$ & $(0,2862)$ & $(0,0559)$ \\
\hline \multirow[t]{2}{*}{ Quantil .40 } & $* * * 1,3337$ & $* * * 0,7448$ & $* * * 1,4015$ & $* * * 0,4230$ \\
\hline & $(0,2242)$ & $(0,0573)$ & $(0,2559)$ & $(0,0721)$ \\
\hline \multirow[t]{2}{*}{ Quantil .50 } & $* * * 1,6146$ & $* * * 0,7599$ & $* * * 1,6265$ & $* * * 0,4515$ \\
\hline & $(0,2926)$ & $(0,0920)$ & $(0,1975)$ & $(0,0799)$ \\
\hline
\end{tabular}

10 Embora também sempre exista a possibilidade de serem captados efeitos de variáveis não observadas. Entretanto, é razoável supor que os efeitos destas sejam apenas residuais e que não se distribuam de maneira sistematicamente diferente entre os grupos. Aspectos críticos em relação à mensuração dos atributos não observáveis dos trabalhadores podem ser encontrados, por exemplo, em Funkhouser (1996), Maloney $(1998,1999,2004)$ e Marcoullier, Castilla e Woodruff (1997). 
Tabela 6 (continuação)

\begin{tabular}{|c|c|c|c|c|}
\hline \multirow[t]{2}{*}{ Quantil } & \multicolumn{2}{|r|}{2002} & \multicolumn{2}{|r|}{2012} \\
\hline & CP\&E & Empregados & CP\&E & Empregados \\
\hline \multirow[t]{2}{*}{ Quantil .60 } & $* * * 1,7948$ & $* * * 0,6238$ & $* * * 1,5598$ & $* * * 0,4046$ \\
\hline & $(0,3809)$ & $(0,1322)$ & $(0,2160)$ & $(0,0927)$ \\
\hline \multirow[t]{2}{*}{ Quantil .70 } & $* * * 1,9245$ & $* * * 0,5385$ & $* * * 1,9757$ & ** 0,4011 \\
\hline & $(0,6813)$ & $(0,1436)$ & $(0,2497)$ & $(0,1758)$ \\
\hline \multirow[t]{2}{*}{ Quantil .80 } & 1,3437 & * 0,2430 & $* * * 1,9563$ & $* * 0,3242$ \\
\hline & $(1,0469)$ & $(0,1408)$ & $(0,3202)$ & $(0,1355)$ \\
\hline \multirow[t]{2}{*}{ Quantil .90 } & $* * * 1,2321$ & 0,0000 & $* * * 2,0858$ & 0,1118 \\
\hline & $(0,4055)$ & $(0,3930)$ & $(0,3250)$ & $(0,1830)$ \\
\hline \multirow[t]{2}{*}{ Quantil.99 } & $* * * 1,4961$ & $-0,6249$ & $* * 3,3173$ & 0,1841 \\
\hline & $(0,4653)$ & $(2,2388)$ & $(1,4339)$ & $(0,8240)$ \\
\hline
\end{tabular}

Fonte: Elaboração própria, com base em resultados da pesquisa.

(): erros-padrão

*** Significativo a 1\%; ** Significativo a 5\%; * Significativo a $10 \%$.

No caso dos empregados, as diferenças tendem a apresentar um comportamento quase contínuo de queda na base, enquanto que entre o segundo e o quarto quintil os valores praticamente não se alteram, e passam a ser não significativos no último quintil. Entre 2002 e 2012, observa-se um aumento da segmentação no primeiro quantil, bem como no octogésimo, ao passo que a mesma tende a sofrer alguma redução nos quantis mais centrais. As Figuras 2 a 5 apresentam os efeitos de tratamento para todos os quantis, bem como seus respectivos intervalos de confiança ao nível de $95 \%$.

Figura 2 Efeitos de tratamento para a formalidade sobre o logaritmo dos rendimentos - conta própria e empregadores - 2002

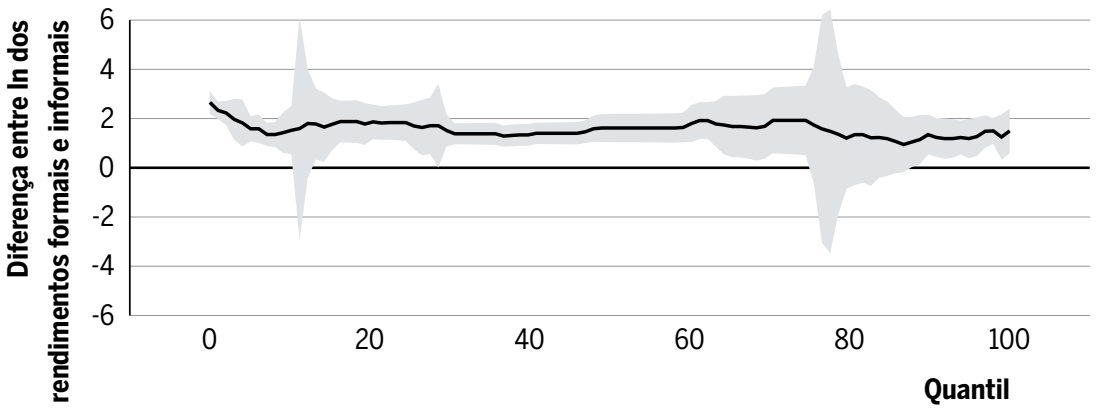

Fonte: Elaboração própria, com base em resultados da pesquisa. 
Figura 3 Efeitos de tratamento para a formalidade sobre o logaritmo dos rendimentos

- conta própria e empregadores - 2012

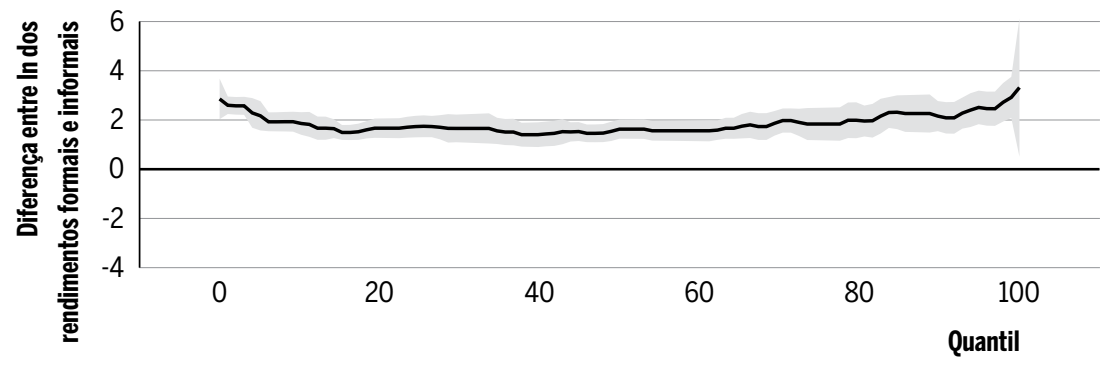

Fonte: Elaboração própria, com base em resultados da pesquisa.

Figura 4 Efeitos de tratamento para a formalidade sobre o logaritmo dos rendimentos

- empregados - 2002

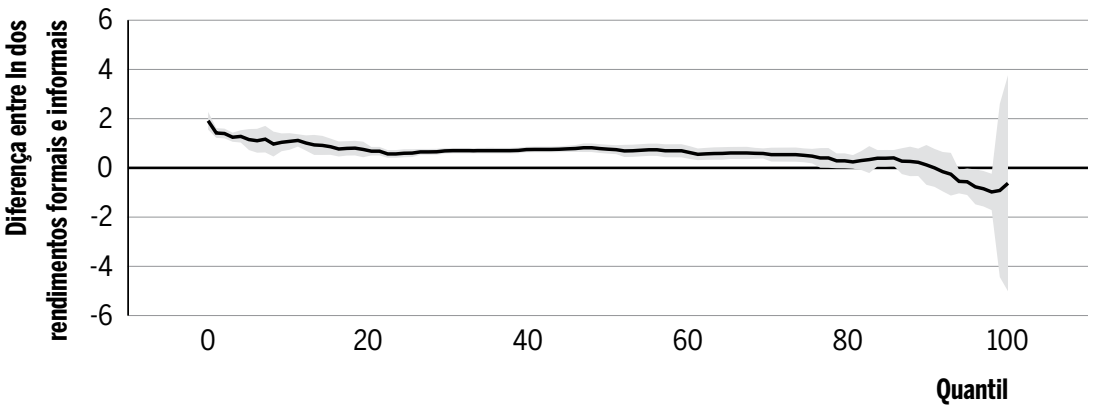

Fonte: Elaboração própria, com base em resultados da pesquisa.

Figura 5 Efeitos de tratamento para a formalidade sobre o logaritmo dos rendimentos

- empregados - 2012

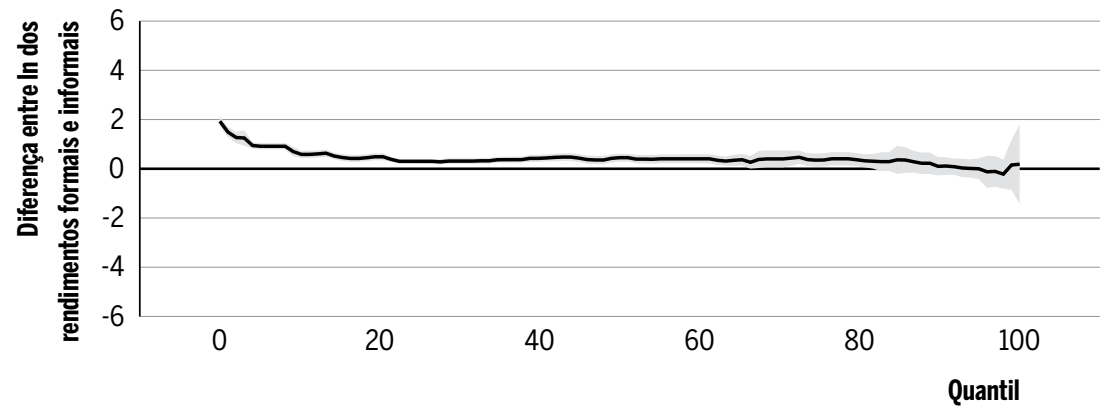

Fonte: Elaboração própria, com base em resultados da pesquisa. 
No caso dos trabalhadores por conta própria e empregadores, nota-se uma maior variância dos rendimentos, o que reflete em intervalos de confiança maiores. Em 2002, essa grande variabilidade não permitiu que alguns coeficientes estimados fossem estatisticamente significativos, especialmente no intervalo que compreende os quantis $75^{\circ}$ ao $85^{\circ}$. Já em 2012 , todos os quantis apresentaram-se significativos ao nível de $1 \%$, exceto pelo $99^{\circ}$, que o foi a $5 \%$. Percebe-se para tal ano um comportamento dos diferenciais semelhante a uma leve forma de " $U$ ", isto é, com maiores diferenças nas extremidades.

Para os empregados, as diferenças são menores, decaindo a partir da base, onde a segmentação é mais intensa, e chegando a se tornar insignificantes nos quantis finais, em geral após o $80^{\circ}$ quantil - muito embora em 2002 existam alguns quantis nessa parte com diferenças significativas, entre o $83^{\circ}$ e o $85^{\circ}$, e entre o $93^{\circ}$ e o $97^{\circ}$ quantis, mais especificamente, sendo que neste último caso as diferenças são negativas, apontando para uma vantagem de rendimentos do lado dos informais. Nos dois anos o comportamento dos diferenciais é ligeiramente similar à forma de um "S" na horizontal. Uma maneira de vislumbrar melhor essas diferenças e seus comportamentos é tomar o antilogaritmo dos resultados, que fornece a razão dos rendimentos em nível, e apresentá-los em uma mesma imagem, a Figura 6.

Figura 6 Razões de rendimento formal/informal para empregados e trabalhadores por conta própria e empregadores - 2002 e 2012

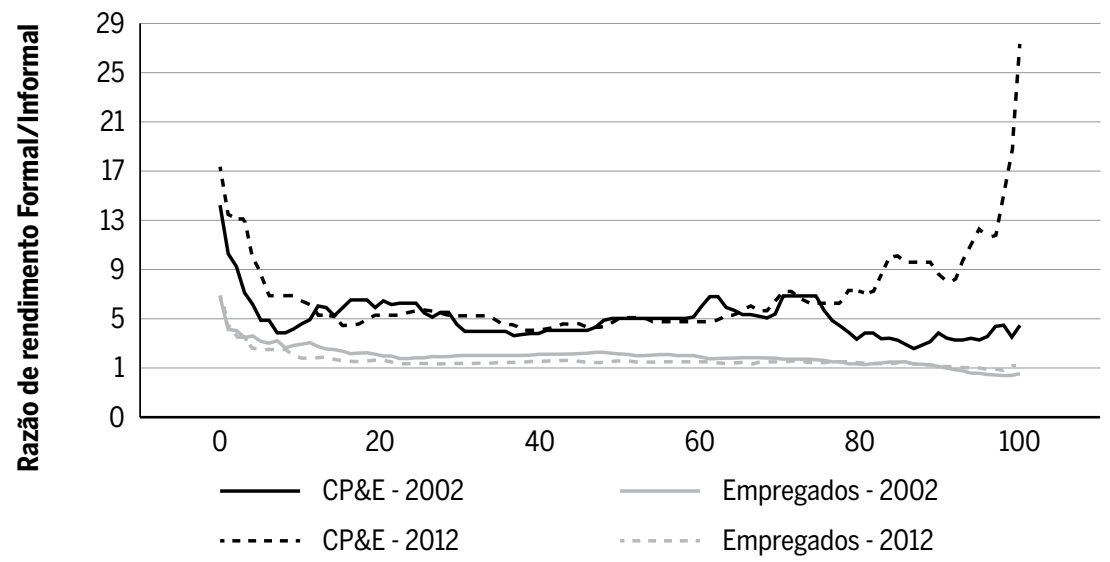

Fonte: Elaboração própria, com base em resultados da pesquisa. 
De maneira geral, nota-se que os trabalhadores informais possuem rendimentos inferiores aos formais em praticamente todos os pontos da distribuição, mas a maior penalização para tal grupo tende a se situar na base dos rendimentos, com o caso extremo do $1^{\circ}$ quantil, em que os formais observam ganhos 17 vezes superiores aos informais, no caso dos trabalhadores por conta própria e empregadores; e de quase 7 vezes no caso dos empregados. Nesse sentido, é preciso ressaltar a relevância das estimativas para os quantis mais extremos $\left(1^{\circ}\right.$ e $\left.99^{\circ}\right)$, e suas consideráveis diferenças em relação aos quantis mais tradicionalmente analisados pela literatura nesses casos (como o $10^{\circ}$ e o $\left.90^{\circ}\right)$.

Não obstante, apesar do diferencial de rendimentos se reduzir substancialmente após os quantis iniciais, ele permanece estatisticamente significativo e relevante entre os trabalhadores de renda média, e em alguns casos até mesmo entre os de maiores rendimentos, sobretudo entre autônomos e empregadores.

No que se refere especificamente aos empregados, como entre os quantis mais elevados, a segmentação é em geral inexistente, é razoável supor que para os trabalhadores em tais pontos da distribuição de rendimentos a informalidade possa de fato ser uma escolha. Como se tratam em geral de indivíduos de maior renda, geralmente lhes é possibilitado procurar por um emprego melhor por mais tempo, de forma que postos formais ou informais constituem um elemento adicional em seu processo de seleção. A isso, soma-se o fato de que a informalidade é substancialmente reduzida entre tal grupo (como apresentado na Tabela 5), o que sugere uma maior disponibilidade relativa de postos formais e que aqueles indivíduos que ainda permanecem em tal situação o fazem por escolha própria, isto é, como fruto de uma estratégia ocupacional, como sugere Maloney (1998).

Também é importante notar um quadro de melhora entre os períodos para o caso dos empregados, uma vez que as diferenças verificadas apresentaram comportamento de queda na maior parte da distribuição, indicando uma segmentação mais fraca em 2012 do que em 2002 para tal grupo. Tal evolução pode ser vista como reflexo do crescimento econômico ocorrido no período, que se deu concomitantemente a uma melhoria na distribuição de renda ${ }^{11}$ e do nível educacional, ${ }^{12}$ fatores fundamentais

11 De acordo com dados do Banco Mundial, o Índice de Gini do Brasil passou de 0,586 em 2002 para 0,527 em 2012. Disponível em: <http://data.worldbank.org/indicator/SI.POV.GINI>. 12 Além das informações amostrais aqui apresentadas, dados do Programa das Nações Uni- 
para que os mercados de trabalho sejam menos desiguais. Contudo, nota-se também que entre os cinco primeiros quantis a evolução foi muito pequena, tendo inclusive aumentado ligeiramente entre os dois primeiros quantis, de modo que não é possível atestar uma atenuação da segmentação entre os empregados no extremo inferior dos rendimentos.

No caso dos empregadores e trabalhadores por conta própria, ocorreu uma intensificação da segmentação na base, notadamente até o $12^{\circ}$ quantil, e no topo, a partir do $75^{\circ}$. Os motivos para tanto não são evidentes. No que se refere à base, uma possível explicação pode estar no aumento relativo dos trabalhadores formais de tal grupo de forma mais intensa entre os primeiros quantis de rendimento (Tabela 5), o que pode ser um indício de que os trabalhadores que permaneceram na informalidade foram aqueles de menor renda - e portanto menor capacidade de arcar com a previdência - entre tal segmento. Em outros termos, isso equivaleria a dizer que a intensificação do fenômeno poderia ser decorrente de um processo em que o progresso de alguns ocorre concomitantemente à estagnação dos demais. Entretanto, como as PNADs não acompanham os mesmos indivíduos no tempo, não é possível atestar isso ao nível individual, e extrapolar conclusões pode conduzir a uma falácia ecológica. Esse aspecto constitui uma sugestão para possíveis investigações futuras.

Para aqueles no quartil superior, a intensificação das diferenças é ainda mais notável. Em tal região tendem a se encontrar donos de empreendimentos de maior porte, cujos rendimentos serão consideravelmente mais elevados e que muito provavelmente serão contribuintes para a previdência, dado que tal contribuição representa uma fração muito pequena de seus ganhos. Notadamente, entre a parcela daqueles com os rendimentos situados no $1 \%$ mais elevado, os formais chegam a observar ganhos 27 vezes superiores aos informais.

Como forma de testar o possível impacto dos empregadores neste resultado, realizou-se uma estimação sem os mesmos, mantendo apenas os autônomos, mas os resultados permaneceram praticamente inalterados. Uma possível justificativa para a não contribuição para a previdência daqueles com maior rendimento é dada por Machado, Oliveira e Antigo (2008), que sugerem que entre esses indivíduos a percepção de maiores rendimentos os anos passou de 5,6 anos em 2000 para 7,2 anos em 2012. Disponível em: <http://hdr.undp. org/en/content/mean-years-schooling-adults-years>. 
induz a preferirem a não contribuição, uma vez que seu custo seria maior e seu rendimento líquido, portanto, menor. Entretanto, não é claro o motivo pelo qual aqueles que contribuem tenham um diferencial de rendimentos tão superior. Nesse sentido, requer-se cautela na interpretação dos resultados, uma vez que também podem refletir a escolha do instrumento. Diante disso, investigar detalhadamente possíveis causas e dimensões desse fenômeno soma-se às sugestões para pesquisas vindouras.

Os resultados ora encontrados são semelhantes àqueles encontrados por Tannuri-Pianto e Pianto (2002), que apontam justamente para uma maior segmentação na base da distribuição de rendimentos dos empregados, mesmo após controlar pelas características não observáveis. Da mesma forma, Ulyssea (2007) encontra resultados que apontam para um aumento do diferencial de rendimentos entre formais e informais entre 2001 e 2005, e conclui que os mais prejudicados por tal movimento foram os trabalhadores mais pobres, embora tal trabalho não aborde separadamente empregados e trabalhadores por conta própria e empregadores, considerando-os apenas como variáveis de controle. Ainda, Bargain e Kwenda (2009) também apontam que a segmentação é mais evidente para os trabalhadores de baixos rendimentos, não somente no Brasil, mas também no México e na África do Sul, o que pode indicar a existência de um padrão entre países emergentes.

Diferentemente de tais trabalhos, no entanto, os resultados aqui apresentados dizem respeito a um contexto mais atual e avançam no sentido de analisar separadamente os empregados dos trabalhadores por conta própria e empregadores, utilizando critérios diferentes de informalidade para tais grupos, e também ao considerar a endogeneidade da alocação formal-informal em relação à renda do trabalhador, utilizando variáveis instrumentais para superar tal dificuldade.

Outro aspecto diferencial de relevância refere-se à dimensão mensurada da segmentação. No que tange à base da distribuição, Tannuri-Pianto e Pianto (2002) encontram diferenças no quinto quantil da ordem de $27 \%$ em favor dos empregados com carteira em 1999; Botelho e Ponczek (2007) estimam esse diferencial em 15\% no primeiro quartil entre 1995 e 2001, e Tannuri-Pianto e Pianto (2016) chegam a um valor de $55 \%$ no primeiro decil para o ano de 2014. Já no presente trabalho, os gaps para os empregados em 2012 atingem 100\% no primeiro decil, e 35\% no primeiro quartil. Se for considerado apenas o primeiro quantil, o diferencial ora obtido para os 
empregados pode chegar a mais de 500\%, mas nesse caso não há estimação diretamente comparável nos demais trabalhos.

Parte dessa diferença de resultados pode ser atribuída à escolha do método, enquanto outra parcela pode advir da endogeneização do tratamento: ao utilizar o mesmo método, mas considerando o efeito de tratamento como exógeno (abordagem que foi descartada pelos resultados dos testes), os diferenciais sofrem razoável redução. ${ }^{13}$

Assim, ressalta-se aqui não apenas que o fenômeno da segmentação formal-informal parece ser bastante relevante no caso brasileiro, mas também que ele pode ser consideravelmente mais intenso do que previamente atestado pela literatura. Contudo, é necessário fazer a ressalva de que, mesmo diante desses resultados e da consistência empírica em relação aos demais trabalhos, existem barreiras práticas que não permitem atestar que as diferenças de rendimentos sejam condição suficiente para a ocorrência de segmentação, como notado por Barros e Ulyssea (2010) e Ulyssea (2010), dado que tais diferenças podem surgir mesmo em contextos de mercados completamente integrados. Não obstante, o fato de os resultados persistirem diante de diferentes abordagens e recortes, e após a inclusão de controles por atributos individuais e dos postos de trabalho, levanta razoáveis suspeitas de que o fenômeno existe, ao menos na base da distribuição de rendimentos.

De forma geral, as evidências ora apresentadas revelam que, mesmo após uma década de expansão da renda, aumento da qualidade de vida e crescimento do emprego no país, sobretudo com elevação dos empregos formais e redução dos informais, há indícios de que a segmentação entre trabalhadores formais e informais permanece presente e relevante, afetando diversas classes de rendimento, mas especialmente aquelas em condições de maior precariedade. A persistência do fenômeno também não pode ser dissociada de suas características regionais, visto que a composição das forças de trabalho formais e informais pouco se alterou entre as grandes regiões e as regiões metropolitanas e não-metropolitanas.

Dado que a formalidade ainda constitui parcela bastante significativa dos trabalhadores brasileiros, é de suma importância que se busque com-

13 As maiores diferenças de rendimento obtidas considerando o tratamento exógeno foram de $245 \%$ para o critério da carteira, e $100 \%$ para o critério da contribuição para a previdência. O mesmo padrão ocorre no exercício que Frölich e Melly (2008) utilizam para exemplificar o método. 
preender a dimensão da segmentação em relação à formalidade, e que se investiguem as possíveis causas por trás de tal fenômeno ${ }^{14}$, bem como suas características para grupos e contextos específicos, além de possibilidades de políticas públicas a ele direcionadas. Enquanto que o presente trabalho buscou atender a primeira questão, as demais demandam novas e atualizadas investigações.

\section{Considerações finais}

O debate a respeito da existência ou não de uma dualidade formal-informal no mercado de trabalho brasileiro e de suas possíveis implicações é bastante extenso, como reflexo das diferentes visões e resultados encontrados por diversos autores. Dentro desse contexto, e diante da carência de investigações mais recentes que levem em consideração empregados e trabalhadores por conta própria e empregadores separadamente e associados a diferentes critérios de informalidade, o presente trabalho procurou investigar a ocorrência de segmentação entre trabalhadores formais e informais, utilizando um modelo quantílico de efeitos de tratamento com o objetivo de verificar a ocorrência de diferenças entre os rendimentos dos trabalhadores formais e informais, atribuíveis unicamente à alocação entre esses setores.

Como o trabalhador pode se autosselecionar no setor formal ou no informal, surge um problema de endogeneidade muitas vezes ignorado em trabalhos desse tipo. No presente caso, tal problema foi superado pela utilização de um modelo de efeitos de tratamento que permite a utilização de variáveis instrumentais. As variáveis escolhidas para instrumentalizar os critérios de informalidade foram o tempo de deslocamento para o tra-

14 Não constitui objetivo deste trabalho adentrar na seara especulativa a respeito das causas da segmentação. Na literatura sobre o tema, diferentes autores elencam possíveis fatores de impacto sobre a segmentação, mas não é possível atestar aqui a presença específica de algum deles no contexto ora apresentado. Investigações sobre aspectos causais para o mercado de trabalho brasileiro, inclusive utilizando as mensurações ora obtidas, adicionam-se às sugestões para desenvolvimentos futuros. Eentre algumas possíveis causas a serem investigadas pode-se elencar: fatores institucionais, como o salário mínimo, as regras de formalização e seus custos (Rauch, 1991; Fortin, Marceau e Savard, 1997; e Ulyssea, 2013); restrições de oferta de postos formais de trabalho, levando à formação de "filas" pela formalidade (Thurow, 1975; Maloney, 1998); ações conjuntas de trabalhadores e/ou empregadores, por meio de sindicatos (Kerr, 1954), bem como aspectos demográficos. Para o Brasil, uma literatura atualizada pode ser encontrada na coletânea organizada por Barbosa Filho, Ulyssea e Veloso (2016). 
balho, no caso da formalidade pela carteira de trabalho (utilizada para os empregados) e a presença de sócio ou estabelecimentos com mais de dez funcionários, no caso da formalidade pela contribuição para a previdência (utilizada para os trabalhadores por conta própria e empregadores).

Os resultados obtidos evidenciam que substanciais diferenças de rendimentos entre trabalhadores formais e informais se devem unicamente pela alocação entre tais setores, o que indica a ocorrência de segmentação nesse sentido. Verifica-se que os trabalhadores mais prejudicados por tal segmentação são aqueles com menores rendimentos, situados na base da distribuição. Tais trabalhadores são justamente aqueles em maior condição de vulnerabilidade e precariedade, pois, além de não poderem desfrutar dos benefícios providos por sistemas de seguridade, sofrem prejuízos nos rendimentos por pertencerem ao setor informal.

Apesar da segmentação ser menor nos quantis intermediários, não é possível descartar sua ocorrência para trabalhadores em tal estrato, inclusive ocorrendo uma intensificação do fenômeno no topo da distribuição para os trabalhadores por conta própria e empregadores. Com tais constatações, parece razoável atestar que a segmentação é fator persistente de prejuízo aos trabalhadores informais ao longo da década analisada, não desaparecendo totalmente mesmo com os acréscimos de rendimentos. No caso dos empregados, esse diagnóstico também permite contestar a ideia de que a decisão de se trabalhar no setor informal (sem carteira assinada) é meramente estratégica e com vistas a compensar os custos da formalidade. Para que tal argumento fosse válido, seria necessário que os rendimentos na informalidade se tornassem maiores que na formalidade, onde, além da remuneração, o indivíduo recebe os benefícios advindos da seguridade social.

Embora a informalidade tenha se reduzido ao longo dos anos recentes, seus impactos sobre os indivíduos e sobre o mercado de trabalho brasileiro permanecem relevantes, de modo que não é possível ignorar as barreiras existentes à formalização, bem como seus prejuízos aos trabalhadores informais, especialmente os de menor renda. Além disso, uma comparação dos resultados aqui obtidos com estudos prévios sugere que o fenômeno da segmentação pode ser mais intenso do que o verificado por outros autores. Tais constatações podem fornecer luz a novas investigações direcionadas para averiguar as causas desse fenômeno e de possíveis políticas públicas que caminhem no sentido de reduzir as barreiras à formalidade. 
Ainda, dado que a principal limitação deste artigo é não se aprofundar em análises para grupos mais específicos, reitera-se a necessidade de aprofundamentos em estudos futuros, abrangendo outros recortes regionais e individuais e especialmente a força de trabalho feminina, de modo a buscar melhor compreensão sobre o fenômeno em diferentes contextos e grupos.

\section{Referências}

ALMEIDA, A. L. O.; ALVES, L. F.; GRAHAM, S. E. M. Poverty, deregulation and employment in the informal sector of Mexico. World Bank, Education and Social Policy Department, 1995.

AVERITT, R. T. The dual economy: the dynamics of American industry. New York: W. W. Norton and Co. Inc., 1968.

BARBOSA FILHO; F. H.; ULYSSEA, G.; VELOSO, F. (orgs.) Causas e consequências da informalidade no Brasil. Rio de Janeiro: Elsevier, 2016.

BARBOSA FILHO, F. H.; VELOSO, F. Fatos estilizados da informalidade do trabalho no Brasil. In: BARBOSA FILHO; F. H.; ULYSSEA, G.; VELOSO, F. (orgs.) Causas e consequências da informalidade no Brasil. Rio de Janeiro: Elsevier, 2016.

BARGAIN, O.; KWENDA, P. The informal sector wage gap: new evidence using quantile estimations on panel data. Discussion Paper n. 4286. Institute of Labor Economics (IZA), 2009.

BARROS, R. P.; VARANDAS, S. A carteira de trabalho e as condições de trabalho e remuneração dos chefes de família no Brasil. Revista da Anpec, v. 10, n. 12, p. 15-20, 1987.

BARROS, R. P.; REIS, J. G. A.; RODRIGUEZ, J. S. Segmentação no mercado de trabalho: a carteira de trabalho na construção civil. Revista de Econometria, v. 10, n. 2, p. 313-335, 1990.

BARROS, R. P.; MELLO, R.; PERO, V. Informal labor contracts: a solution or a problem? Texto para Discussão, n. 291. IPEA, 1993.

BARROS, R. P.; ULYSSEA, G. On the empirical content of the formal-informal labor market segmentation hypothesis. Brazilian Review of Econometrics, v. 30, n. 2, p. 289-310, 2010.

BECKER, G. S. Investment in human capital: a theoretical analysis. The Journal of Political Economy, v. 70, n. 5, p. 9-49, 1962.

BLUESTONE, B. The tripartite economy: labour markets and the working poor. Poverty and Human Resources Abstracts, v. 5, n. 4, p. 15-35, 1970.

BORJAS, G. J.; MINCER, J. The distribution of earnings profiles in longitudinal data. Working Paper n. 143. The National Bureau of Economic Research (NBER), 1976.

BOTELHO, F.; PONCZEK, V. Segmentation in the Brazilian Labor Market. Texto para Discussão 231. Escola de Economia de São Paulo da Fundação Getúlio Vargas (FGV-EESP), 2007.

BUCHINSKY, $M$. The dynamics of changes in the female wage distribution in the USA: A quantile regression approach. Journal of Applied Econometrics, v. 13, n. 1, p. 1-30, 1998.

CAIRNES, J. E. Some leading principles of political economy newly expounded. New York: Harper \& Brothers, 1878. 
CARNEIRO, F. G.; HENLEY, A. Modelling formal vs. informal employment and earnings: micro-econometric evidence for Brazil. Encontro Nacional de Economia. Anais. ANPEC, 2001.

CORSEUIL, C. H.; FOGUEL, M. N. Uma sugestão de deflatores para rendas obtidas a partir de algumas pesquisas domiciliares do IBGE. Texto para Discussão n. 0897. Instituto de Pesquisa Econômica Aplicada (IPEA), 2002.

DOERINGER, P. B.; PIORE, M. J. Internal labor markets and manpower analysis. Lexington (MA): Heath Lexington Books, 1971.

FERNANDES, R. Mercado de trabalho não-regulamentado: participação relativa e diferenciais de salários. Pesquisa e Planejamento Econômico, v. 26, n. 3, p. 417-442, 1996.

FIELDS, G. S. Labour market modelling and the urban informal sector: theory and evidence. In: TURNHAM, D.; SALOMÉ, B.; SCHWARZ, A. (eds.). The informal sector revisited. Paris: Organisation for Economic Co-operation and Development, 1990.

FORTIN, B.; MARCEAU, N.; SAVARD, L. Taxation, wage controls and the informal sector. Journal of Public Economics, v. 66, n. 2, p. 293-312, 1997.

FRÖLICH, M.; MELLY, B. Unconditional Quantile Treatment Effects under endogeneity. Discussion Paper n. 3288, Institute of Labor Economics (IZA), 2008.

FRÖLICH, M.; MELLY, B. Estimation of quantile treatment effects with Stata. The Stata Journal, v. 10, n. 3, p. 423-457, 2010.

FUNKHOUSER, E. The urban informal sector in Central America: household survey evidence. World Development, v. 24, n. 11, p. 1737-1751, 1996.

HARRIS, J. R.; TODARO, M.P. Migration, unemployment, and development: a tow sector analysis. American Economic Review, v. 60, n. 1, p. 126-142, 1970.

HARRISON, B. Education training and the urban ghetto. Baltimore: John Hopkins University Press, 1972.

IBGE - INSTITUTO BRASILEIRO DE GEOGRAFIA E ESTATÍSTICA. Censo Demográfico 2010: características gerais da população, religião e pessoas com deficiência. Rio de Janeiro, 2012a. Disponível em: <https://biblioteca.ibge.gov.br/visualizacao/periodicos/94/ cd_2010_religiao_deficiencia.pdf >. Acesso em: 05 jan. 2016.

IBGE - INSTITUTO BRASILEIRO DE GEOGRAFIA E ESTATÍSTICA. Censo Demográfico 2010: resultados gerais da amostra. Rio de Janeiro, 2012b. Disponível em: <https://ww2. ibge.gov.br/home/presidencia/noticias/imprensa/ppts/0000000847310412201231572748 3985.pdf>. Acesso em: 05 jan. 2016.

KASSOUF, A. L. Wage gender discrimination and segmentation in the Brazilian labor market. Economia Aplicada, v. 2, n. 2, p. 243-269, 1998.

KERR, C. The balkanisation of labour markets. In: BAKKE, E. W. et al. (eds.) Labour mobility and economic opportunity. Cambridge, MA: Technology Press of MIT, 1954.

LEONE, E. T. O perfil dos trabalhadores e trabalhadoras na economia informal. Série trabalho decente no Brasil, Documento de Trabalho n. 3. Brasília: OIT, 2010.

LIMA, R. Mercado de trabalho: o capital humano e a teoria da segmentação. Pesquisa e Planejamento Econômico, v. 10, n. 1, p. 217-272, 1980. 
LEONTARIDI, M. R. Segmented labour markets: theory and evidence. Journal of Economic Surveys, v. 12, n. 1, p. 63-101, 1998.

LOUREIRO, P. R. A.; ARAUJO, R. A.; SOUZA, N. A. An evaluation of the Brazilian informal labor market from 1995 to 2008. Journal of Economic Studies, v. 40, n. 1, p. 71-87, 2013.

MACHADO, A. F.; OLIVEIRA, A. M. H. C.; ANTIGO, M. Evolução do diferencial de rendimentos entre setor formal e informal no Brasil: o papel das características não observadas. Revista de Economia Contemporânea, v. 12, n. 2, p. 355-388, 2008.

MALONEY, W. F. Are LDC labor markets dualistic? Policy Research Working Paper, n. 1941. World Bank, 1998.

MALONEY, W. F. Does informality imply segmentation in urban labor markets? Evidence from sectoral transitions in Mexico. World Bank Economic Review, v. 13, n. 2, 1999.

MALONEY, W.F. Informality revisited. World Development, v. 32, n. 7, p. 1159-1178, 2004.

MARCOULLIER, D. V.; CASTILLA, V. R.; WOODRUFF, C. Formal measures of the informal-sector wage gap in Mexico, El Salvador, and Peru. Economic Development and Cultural Change, v. 45, n. 2, p. 367-92, 1997.

MENEZES-FILHO, N. A.; MENDES, M.; ALMEIDA, E. S. O diferencial de salários formal-informal no Brasil: segmentação ou viés de seleção? Revista Brasileira de Economia, v. 58, n. 2, p. 235-248, 2004.

MEZZERA, J. Informal sector, as in PREALC. International Labor Organization, 1990.

MILL, J. S. Principles of political economy. New York: D. Appleton and Company, 1885.

MINCER, J. Schooling, experience and earnings. New York: National Buereau of Economic Research: Columbia University Press, 1974.

ORGANIZAÇÃO INTERNACIONAL DO TRABALHO - OIT. Decent work and the informal economy. Geneva: ILO, 2002.

ORGANIZAÇÃO INTERNACIONAL DO TRABALHO - OIT. Employment, incomes and equality: a strategy for increasing productive employment in Kenya. Geneva: ILO, 1972.

PERO, V. L. A carteira de trabalho no mercado de trabalho metropolitano brasileiro. Pesquisa e Planejamento Econômico, v. 22, n. 2, p. 305-342, 1992.

PRATAP, S.; QUINTIN, E. Are labor markets segmented in Argentina? A semiparametric approach. Discussion Paper 02-02. Instituto Tecnológico Autónomo de México, 2002.

RAUCH, J. E. Modeling the informal sector formally. Journal of Development Economics, v. 35, n. 1, p. 33-47, 1991.

SCHULTZ, T. W. Investment in human capital. The American Economic Review, v. 51, n. 1, p. 1-17, 1961.

SEDLACEK, G. L.; BARROS, R. P.; VARANDAS, S. Segmentação e mobilidade no mercado de trabalho: a carteira de trabalho em São Paulo. Pesquisa e Planejamento Econômico, v. 20, n. 1, p. 87-104, 1990.

TANNURI-PIANTO, M.; PIANTO, D. Informal employment in Brazil - a choice at the top and segmentation at the bottom: a quantile regression approach. Anais do XXIV Encontro Brasileiro de Econometria, v. 2, 2002. 
TANNURI-PIANTO, M.; PIANTO, D. Mercado de trabalho informal no Brasil: escolha ou segmentação? In: BARBOSA FILHO, F. H.; ULYSSEA, G.; VELOSO, F. (orgs.) Causas e consequências da informalidade no Brasil. Rio de Janeiro: Elsevier, 2016.

TANSEL, A.; KAN, E. O. The formal/informal employment earnings gap: evidence from Turkey. Discussion Paper 2012/23. Turkish Economic Association, 2012.

THUROW, L. C. Generating inequality. New York: McMillan Press, 1975.

ULYSSEA, G. Informalidade no mercado de trabalho brasileiro: uma resenha da literatura. Revista de Economia Política, v. 26, n. 4, p. 596-618, 2006.

ULYSSEA, G. Segmentação no mercado de trabalho e desigualdade de rendimentos no Brasil: uma análise empírica. Texto para Discussão, n. 1261. Instituto de Pesquisa Econômica Aplicada (IPEA), 2007.

ULYSSEA, G. The formal-informal labor market segmentation hypothesis revisited. Brazilian Review of Econometrics, v. 30, n. 2, p. 311-334, 2010.

ULYSSEA, G. Informalidade e desempenho econômico: uma análise dos impactos micro e macroeconômicos de políticas para a formalização. Texto para Discussão n. 1900. Instituto de Pesquisa Econômica Aplicada (IPEA), 2013.

\section{Sobre os autores}

Cassiano Ricardo Dalberto - cassianord@gmail.com

Centro Socioeconômico (CSE), Universidade Federal de Santa Catarina, Florianópolis, Santa Catarina.

JaderFernandes Cirino-jader.cirino@ufv.br

Departamento de Economia (DEE), Universidade Federal de Viçosa, Viçosa, Minas Gerais.

\section{Sobre o artigo}

Recebido em 06 de janeiro de 2016. Aprovado em 20 de fevereiro de 2017. 


\section{APÊNDICE A}

Os efeitos de tratamento quantílico (quantile treatment effect - OTE) não-condicionais representam a diferença entre os quantis não-condicionais de um produto sob tratamento e os quantis não-condicionais desse mesmo produto sob a ausência de tratamento. A diferença deste método em relação aos QTE condicionais - que são condicionados às covariadas utilizadas para controle - é que ele sumariza os efeitos de um tratamento para toda a população e, por isso, possuem maior apelo na avaliação de políticas públicas. Em outros termos, os QTE não-condicionais são uma função unidimensional dos quantis, enquanto que os QTE condicionais são funções multidimensionais dos quantis e das covariadas. $O$ método a seguir descrito é introduzido por Frölich e Melly (2008) - de onde são tomadas diretamente todas as definições - e permite a utilização dos QTE não-condicionais para o caso de tratamentos endógenos com a utilização de variáveis instrumentais.

Segundo Frölich e Melly (2008), em tal arcabouço o instrumento $Z$ pode ser independente do produto $Y$ apenas de maneira condicional a um conjunto de covariadas $X$, motivo pelo qual, ainda que o estimador seja não-condicional, a inclusão das mesmas é útil para o método, uma vez que possibilita a identificação do impacto indireto do instrumento em $Y$.

Considerando-se $Y_{i}^{1}$ e $Y_{i}^{0}$ como os produtos potenciais do indivíduo $i$, sendo $Y_{i}^{1}$ o produto observado em caso de o indivíduo receber o tratamento $D(D=1)$, e $Y_{i}^{0}$ o produto na ausência desse tratamento $(D=0)$; e assumindo $Q_{Y^{1}}^{\tau}$ e $Q_{Y^{0}}^{\tau}$ como suas respectivas versões quantílicas no quantil $\tau$, o efeito de tratamento quantílico (OTE) pode ser definido pela diferença entre ambos:

$$
\Delta^{\tau}=Q_{Y^{1}}^{\tau}-Q_{Y^{0}}^{\tau}
$$

Um problema comum na mensuração dos efeitos de tratamento, entretanto, é a endogeneidade de $D$. Sob tal situação, tem-se:

$$
\begin{aligned}
& Y_{i}=\varphi\left(D_{i}, X_{i}, U_{i}\right) \\
& D_{i}=\varsigma\left(Z_{i}, X_{i}, V_{i}\right)
\end{aligned}
$$


em que $U$ e $V$ são variáveis não observáveis possivelmente relacionadas entre si e $X$ são covariadas adicionais que podem ser correlacionadas com $U$ e/ou $V$. Assume-se que após a inclusão de $X$ no modelo, $Z$ é excluído da função $\varphi$. Os produtos potenciais então podem ser expressos por:

$$
\begin{aligned}
& Y_{i}^{d}=\varphi\left(d, X_{i}, U_{i}\right) \\
& D_{i}^{z}=\varsigma\left(z, X_{i}, V_{i}\right)
\end{aligned}
$$

Assim, impõe-se a restrição de triangularidade, isto é, $Y$ não entra em $\varsigma$. Também é necessário que $\varsigma$ seja fracamente monotônica em seu primeiro argumento, o que equivale a dizer que um aumento exógeno em $Z_{i}$ nunca pode reduzir o valor de $D_{i}$.

A análise então é focada no sub-grupo dos compliers, que são os indivíduos que respondem a uma mudança em $Z$ dentro da região de suporte de $Z$. De acordo com o tratamento, a população pode ser dividida em quatro grupos: $T_{i}=a$ se $D_{i}^{1}=D_{i}^{0}=1$ (sempre tratados), $T_{i}=n$ se $D_{i}^{1}=D_{i}^{0}=0$ (nunca tratados), $T_{i}=c$ se $D_{i}^{1}>D_{i}^{0}$ (compliers) e $T_{i}=d$ se $D_{i}^{1}<D_{i}^{0}$ (defiers). Geralmente não é possível identificar o efeito de $D$ em $Y$ para os indivíduos para os quais $D_{i}^{z}$ não varia $\operatorname{com} z$ na região de suporte de $Z$. Caso os instrumentos $Z$ sejam fortes o suficiente para mover todos os indivíduos de $D_{i}=0$ para $D_{i}=1$, tem-se o efeito de tratamento médio (average treatment effect-ATE), $E\left[Y^{1}-Y^{0}\right]$ para toda a população. Entretanto, esse geralmente não é o caso, de forma que é preciso considerar os efeitos sobre a maior subpopulação para a qual os efeitos podem ser identificados. Assim, o efeito é focado sobre os compliers:

$$
\Delta_{c}^{\tau}=Q_{Y^{1} \mid c}^{\tau}-Q_{Y^{0} \mid c}^{\tau}
$$

em que $Q_{Y^{1} \mid c}^{\tau}=\inf \operatorname{Pr}\left(Y^{1} \leq q \mid T=c\right) \geq \tau$, onde $T_{i}=c$ significa que o indivíduo $i$ é um complier.

Se $Z$ é uma única variável binária e possui um impacto ao menos fracamente monotônico em $D$, a maior subpopulação afetada por uma mudança no instrumento será dada por aqueles indivíduos para quem $D_{i}^{1}>D_{i}^{0}$. De modo mais geral, a maior subpopulação afetada será obtida ao se mover $Z$ de seu menor valor em sua região de suporte para seu maior valor. No caso de um único instrumento com região de suporte $Z=\left[z_{\min }, z_{\max }\right]$, 
isso corresponde a hipoteticamente mover $Z_{i}$ de $z_{\text {min }}$ para $z_{\max }$. Sendo o instrumento binário, isso equivale a mover $Z_{i}$ de 0 para 1.

Duas suposições são necessárias para o método:

\section{Suposição 1}

- Existência de compliers: $\operatorname{Pr}(T=c)=P_{c}>0$

- Monotonicidade: $\operatorname{Pr}(T=d)=0$

- Independência do instrumento: $\left(Y^{d}, T\right) \perp Z \mid X$

- Suporte comum: $0<p(X)<1$, a.s. onde $p(x)=\operatorname{Pr}(Z=1 \mid X=x)$

A notação $p(x)$ diz respeito ao escore de propensão (propensity score) em que deve-se notar que ela se refere ao instrumento $Z$, e não ao tratamento $D$, como seria normal.

O item $a$ requer que ao menos alguns indivíduos reajam às mudanças no instrumento; o item $b$ requer que $D_{i}^{z}$ aumente fracamente com $z$ para todos os indivíduos; c é a principal suposição dos métodos de variáveis instrumentais, demandando as restrições de triangularidade (o instrumento $Z_{i}$ não pode afetar o produto potencial $Y_{i}^{d}$ diretamente) e de independência condicional (os indivíduos para os quais $Z=z$, é observado, não devem diferir em suas características não-observáveis relevantes dos indivíduos para os quais $Z \neq z)^{15}$; $d$ requer que o suporte de $X$ seja idêntico nas subpopulações para as quais $Z=0$ e $Z=1$.

\section{Suposição 2}

As variáveis aleatórias $Y^{1} \mid$ c e $Y^{0} \mid$ c são contínuas, com densidade positiva na vizinhança de $Q_{Y^{1} \mid c}^{\tau}$ e $Q_{Y^{0} \mid c}^{\tau}$, respectivamente.

Tal suposição garante que os quantis são únicos e bem definidos.

Assim, sob a suposição 1 acima, a distribuição dos produtos potenciais para os compliers são identificadas não-parametricamente como:

15 A não ser em casos em que o instrumento é atribuído aleatoriamente, essa restrição dificilmente é observada. Contudo, condicional a um conjunto grande de covariadas $\mathrm{X}$, tal suposição é mais plausível. 


$$
\begin{aligned}
& F_{Y^{1} \mid c}(u)=\frac{\int(E[1(Y \leq u) D \mid X, Z=1]-E[1(Y \leq u) D \mid X, Z=0]) d F_{x}}{\int(E[D \mid X, Z=1]-E[D \mid X, Z=0]) d F_{x}} \\
& F_{Y^{0} \mid c}(u)= \\
& =\frac{\int(E[1(Y \leq u)(D-1) \mid X, Z=1]-E[1(Y \leq u)(D-1) \mid X, Z=0]) d F_{x}}{\int(E[D \mid X, Z=1]-E[D \mid X, Z=0]) d F_{x}}
\end{aligned}
$$

A partir de onde se pode obter os QTE, dados pelas diferenças entre os quantis:

$$
Q_{Y^{1} \mid c}^{\tau}=F_{Y^{1} \mid c}^{-1}(\tau) \quad Q_{Y^{0} \mid c}^{\tau}=F_{Y^{0} \mid c}^{-1}(\tau)
$$

Estimadores não-paramétricos existem para todos os elementos em (05). $E[D \mid X=x, Z=z]$ pode ser obtido por um estimador logit local, ou por uma aproximação de série logística. $E[1(Y \leq u) D \mid X, Z=1]$ também pode ser obtido por um logit local diferente para cada $u$.

Os estimadores baseados em (05) podem ser qualificados como estimadores de regressão, ou de matching, dado que correspondem a uma função de várias regressões não-paramétricas em $X$. No caso do tratamento exógeno, as abordagens mais utilizadas são a regressão (ou matching) no escore de propensão e estimadores ponderados baseados no escore de propensão. A aplicação do matching sobre o escore de propensão também pode ser utilizada sobre o presente caso.

Os demais detalhes sobre o método e as demonstrações sobre suas hipóteses e teoremas podem ser verificados diretamente em Frölich e Melly (2008).

No presente artigo, a estimação dos efeitos de tratamento foi realizada utilizando o módulo ivqte do Stata, desenvolvido por Frölich e Melly (2010). As covariadas utilizadas como controle são aquelas apresentadas na Tabela 1, e os instrumentos para as variáveis de tratamento são aqueles descritos na subseção 4.1. 


\section{APÊNDICE B}

Tabela A1 Correlações dos instrumentos com as variáveis instrumentadas

\begin{tabular}{lr|r}
\hline & Correlação (2002) & Correlação (2012) \\
\hline $\begin{array}{l}\text { Formalidade pela carteira } x \\
\text { tempo até trabalho }>30 \text { min }\end{array}$ & 0,0892 & 0,1241 \\
\hline $\begin{array}{l}\text { Formalidade pela previdência } x \\
\text { tinha sócio }\end{array}$ & 0,2758 & 0,2461 \\
\hline
\end{tabular}

Fonte: Elaboração própria.

Tabela A2 Coeficientes dos instrumentos estimados via logit, com a variável instrumentada como dependente ${ }^{1}$

\begin{tabular}{lrr}
\hline & Correlação (2002) & Correlação (2012) \\
\hline $\begin{array}{l}\text { Formalidade pela carteira }(Y) \times \\
\text { tempo até trabalho }>30 \text { min }(X)\end{array}$ & 0,5060 & 0,6910 \\
\hline Formalidade pela previdência $(Y) \times$ & $*^{* *}(0,0298)$ & $* * *(0,0312)$ \\
tinha sócio $(X)$ & 0,6845 & 0,6964 \\
\hline
\end{tabular}

Fonte: Elaboração própria.

(): erro-padrão robusto;

***: coeficiente significativo a 1\%;

1: Todas as estimações utilizaram também as demais variáveis contidas na Tabela 1 como controle

Tabela A3 Testes dos instrumentos e de endogeneidade do tratamento

\begin{tabular}{l|r|r|r|r}
\hline & \multicolumn{2}{|r}{$\begin{array}{r}\text { Formalidade pela } \\
\text { previdência }\end{array}$} & \multicolumn{2}{r}{$\begin{array}{r}\text { Formalidade pela } \\
\text { carteira }\end{array}$} \\
\cline { 2 - 5 } & $\mathbf{2 0 0 2}$ & $\mathbf{2 0 1 2}$ & $\mathbf{2 0 0 2}$ & $\mathbf{2 0 1 2}$ \\
\hline $\begin{array}{l}\text { Teste de subidentificação } \\
\text { (estatística LM da correlação } \\
\text { canônica de Anderson)1 }\end{array}$ & $* * * 234,362$ & $* * * 203,066$ & $* * * 292,316$ & $* * * 473,473$ \\
\hline $\begin{array}{l}\text { Teste de identificação fraca } \\
\text { (estatística F de Kleibergen-Paap) }\end{array}$ & $* * * 179,879$ & $* * * 180,319$ & $* * * 300,760$ & $* * * 511,334$ \\
\hline $\begin{array}{l}\text { Teste de endogeneidade do } \\
\text { tratamento (difference-in-Sargan) }\end{array}$ & $* * * 46,614$ & $* * * 103,856$ & $* * * 22,671$ & $* * * 16,687$ \\
\hline
\end{tabular}

Fonte: Elaboração própria.

***: coeficiente significativo a 1\%;

1: HO: a equação é sub-identificada;

2: HO: a equação é fracamente identificada. 
Tabela A4 Teste de falsificação: correlações dos instrumentos aleatórios com as variáveis instrumentadas

\begin{tabular}{lr|r}
\hline & Correlação (2002) & Correlação (2012) \\
\hline $\begin{array}{l}\text { Formalidade pela carteira } x \\
\text { tempo até trabalho }>30 \text { min }\end{array}$ & 0,0044 & $-0,0002$ \\
\hline $\begin{array}{l}\text { Formalidade pela previdência } x \\
\text { tinha sócio }\end{array}$ & $-0,0083$ & 0,0030 \\
\hline
\end{tabular}

Fonte: Elaboração própria.

Tabela A5 Teste de falsificação: coeficientes dos instrumentos aleatórios estimados via logit, com a variável instrumentada como dependente ${ }^{1}$

\begin{tabular}{lrrr}
\hline & Coeficiente (2002) & Coeficiente (2012) \\
\hline Formalidade pela carteira $(Y) \times$ & 0,0047 & $-0,0012$ \\
tempo até trabalho $>$ 30 $\min (X)$ & $(0,0263)$ & $(0,0268)$ \\
\hline Formalidade pela previdência $(Y) \times$ & $-0,0340$ & 0,0236 \\
tinha sócio $(X)$ & $(0,0398)$ & $(0,0374)$ \\
\hline
\end{tabular}

Fonte: Elaboração própria.

(): erro-padrão robusto;

1: Todas as estimações utilizaram também as demais variáveis contidas na Tabela 1 como controle.

Tabela A6 Testes de falsificação dos instrumentos aleatórios

\begin{tabular}{l|r|r|r|r}
\hline & \multicolumn{2}{|r}{$\begin{array}{r}\text { Formalidade pela } \\
\text { previdência }\end{array}$} & \multicolumn{2}{r}{$\begin{array}{r}\text { Formalidade pela } \\
\text { carteira }\end{array}$} \\
\cline { 2 - 5 } & $\mathbf{2 0 0 2}$ & $\mathbf{2 0 1 2}$ & $\mathbf{2 0 0 2}$ & $\mathbf{2 0 1 2}$ \\
\hline $\begin{array}{l}\text { Teste de subidentificação } \\
\text { (estatística LM da correlação } \\
\text { canônica de Anderson) }\end{array}$ & 0,558 & 1,081 & 0,028 & 0,005 \\
\hline $\begin{array}{l}\text { Teste de identificação fraca } \\
\text { (estatística F de Kleibergen-Paap) }\end{array}$ & 0,557 & 1,079 & 0,028 & 0,005 \\
\hline $\begin{array}{l}\text { Teste de endogeneidade do } \\
\text { tratamento (difference-in-Sargan) }\end{array}$ & 0,916 & $* * 6,435$ & 1,421 & 0,323 \\
\hline
\end{tabular}

Fonte: Elaboração própria.

**: coeficiente significativo a $5 \%$;

1: HO: a equação é subidentificada;

2: HO: a equação é fracamente identificada. 